\title{
2 Wie leben wir ein gutes Leben? Ansätze der Tugendethik
}

\author{
2.1 Ursprünge ethischen Denkens \\ 2.2 Aristoteles' Tugendethik \\ 2.3 Systematische Fragen
}

"Ja, renn' nur nach dem Glück, doch renne nicht zu sehr, denn alle rennen nach dem Glück, das Glück rennt hinterher."

Brecht 1988,

Bd. 2, S. 291

Glücksstreben: Dieser häufig zitierte Ratschlag stammt aus Bertolt Brechts Dreigroschenoper, genauer aus der Ballade von der Unzulänglichkeit menschlichen Planens. Die provokativ-sarkastische Ballade erklärt den Menschen für grundsätzlich unfähig in genau demjenigen, worin die philosophische Ethik über viele Jahrhunderte ihre wichtigste Aufgabe gesehen hat: die Konturen eines guten Lebens zu umreißen und das menschliche Glücksstreben durch vernünftige Überlegung und Selbstkontrolle in gute Bahnen zu lenken. Die Auffassung, dass wir alle nach Glück streben, teilt Brechts moderne Ballade dabei mit den antiken Ethiken des guten Lebens, mit Aristoteles und den Autoren der Stoa, ebenso wie mit Kant und anderen neuzeitlichen Autoren.

Ethik des guten Lebens werden systematische Versuche genannt, die Form eines guten Lebens zu bestimmen und diejenigen vorbildlichen praktischen Haltungen und Charakterzüge zu identifizieren, die ein solches Leben prägen oder ermöglichen. In ähnlichem Sinn wird auch von Glücksethiken gesprochen. Sie unterscheiden sich von Ethiken, die primär Kriterien für die moralische Richtigkeit von Handlungen oder Handlungsnormen zu begründen suchen.

Die Unterschiede liegen in der Einschätzung, inwieweit wir unser Glück selbst in der Hand haben, was unter Glück genauer zu verstehen ist und inwieweit sich überhaupt allgemeine, überpersönlich und zeitlos gültige Aussagen über Inhalt und Bedingungen menschlichen Glücks begründen lassen. Mit den philosophischen Antworten auf diese Fragen und den entsprechenden Überlegungen und Argumenten wird sich dieses Kapitel vor allem beschäftigen. Zugleich wird es in die Anfänge ethischen Denkens in der griechischen Antike einführen. Dabei wird, trotz des zeitlichen Abstands von etwa zweieinhalb Jahrtausenden, vieles erstaunlich vertraut erscheinen. Andererseits wird bei der Lektüre manches begegnen, das aus heutiger Sicht fremd anmutet. Die Erfahrung von Fremdheit gehört zugleich zum Gegenstand. Denn es war und ist regelmäßig die Erfahrung fremdartiger oder befremdlicher Vorstellungen vom guten Leben und ge- 
rechten Verhalten, die eine ethische Reflexion in Gang setzt. Der Eindruck, dass verschiedene Personen oder Gemeinschaften sich an unterschiedlichen Werten orientieren oder unterschiedlichen Normen folgen, provoziert die Frage, ob und inwieweit es überhaupt srichtige Werte und Normen gibt und woran sich ihre Richtigkeit bemisst.

Ethischer Naturalismus: Schon in der vorsokratischen Philosophie und in aller Deutlichkeit durch die Athener Sophisten werden die richtigen Werte und Normen regelmäßig mit denen gleichgesetzt, die von Natur aus gelten. Natur ist auch der primäre Bezugspunkt, wenn Platon, Aristoteles, die Kyniker oder die Stoiker nach dem Wesen eines guten und gelungenen Lebens fragen. Ein gutes und glückliches Leben ist für sie alle gleichbedeutend mit einem naturgemäßen Leben. Dieser ethische Naturalismus hat die Tradition der Moralphilosophie maßgeblich geprägt. Freilich unterscheiden sich etwa Aristoteles' Annahmen über die Natur grundlegend vom heutigen Naturverständnis, das sich seit der frühen Neuzeit in klarer Absetzung von der aristotelischen Tradition durchgesetzt hat. Gleichwohl wird Aristoteles' Ethik auch noch von vielen zeitgenössischen Philosophinnen und Philosophen als aktuell relevantes oder zumindest aktualisierungsfähiges Modell einer Ethik des guten Lebens betrachtet. Dies alles ist Grund genug, Aristoteles' ethisches Denken in diesem Kapitel ausführlicher in den Blick zu nehmen, es aber auch mit späteren Auffassungen zu kontrastieren.

\section{1 | Ursprünge ethischen Denkens}

Ethik und Naturphilosophie: In den frühesten Zeugnissen der griechischen Philosophie steht nicht die Ethik, sondern die Naturphilosophie im Mittelpunkt. Allerdings ist beides zunächst nicht klar geschieden. Im ältesten überlieferten Textfragment denkt der milesische Philosoph Anaximandros (ca. 610-546 v. u. Z.) über den Ursprung aller Dinge, über Werden und Entstehen, aber offenbar zugleich auch über Schuld, Sühne und Gerechtigkeit nach:

Diels/Kranz 1956

(DK, 12A9)

Zur Vertiefung
"Anfang und Ursprung der seienden Dinge [...] ist das Apeiron (das grenzenlos-Unbestimmbare). Woraus aber das Werden ist den seienden Dingen [...], in das hinein geschieht auch ihr Vergehen nach der Schuldigkeit; denn sie zahlen einander gerechte Strafe und Buße für ihre Ungerechtigkeit nach der Zeit Anordnung"

\section{Zitieren philosophischer Klassiker}

Für einige philosophische Klassiker haben sich im akademischen Kontext spezielle Zitierkonventionen durchgesetzt, die (mit Ausnahmen im Interesse der Lesbarkeit) auch in diesem Band befolgt werden. So werden Vorsokratiker üblicherweise nicht nach Seitenzahlen, sondern nach dem Ordnungsschema der Ausgabe von Hermann Diels und Walther Kranz (abgekürzt als DK) zitiert, Platon nach der Zählung der von Henricus 
Stephanus besorgten Stephanus-Ausgabe, Aristoteles nach der auf der Aristoteles-Ausgabe Immanuel Bekkers basierenden Bekker-Paginierung (häufig mit zusätzlicher Angabe der Kapitel und Bücher), Kant nach der Akademieausgabe (Akad.-Ausg. oder schlicht AA), Nietzsche nach der Kritischen Studienausgabe (KSA), und so weiter. Viele - wenn auch leider nicht alle - aktuelle Ausgaben philosophischer Klassiker bemühen sich, diesen Zitierkonventionen durch entsprechende Randnummern oder Seitenkonkordanzen Rechnung zu tragen.

Die hier anklingende Vorstellung einer harmonischen Einheit von Naturordnung einerseits und moralischer Ordnung andererseits, von Naturkausalität und gerechter Vergeltung, scheint aus heutiger Sicht nicht weit entfernt von mythischem Denken oder einer ideologischen Verklärung bestehender Verhältnisse. Sie steht jedoch am Anfang einer philosophischen Reflexionsbewegung, die sich gerade gegen den blinden Glauben an die Gültigkeit der alten Erzählungen und der hergebrachten sittlichen Traditionen wendet und durch vernünftige Überlegung zu überzeugenderen Antworten auf grundlegende Fragen gelangen will. In Anaximandros' Vorstellung einer harmonischen Einheit von Naturordnung und moralischer Ordnung ist zudem ein ethischer Naturalismus angedeutet, der für diese Aufklärungsbewegung viele Jahrhunderte lang, mindestens bis zur frühen Neuzeit, bestimmend war. Schließlich lässt sich diese Vorstellung auch als Idee einer metaphysischen Gerechtigkeit verstehen, von der sich zumindest sagen lässt, dass sie den Gegenstand einer grundlegenden - Kant zufolge sogar unvermeidlichen (KpV, S. 134) - menschlichen Hoffnung bildet.

Orientierung an der Vernunft: Ethik als philosophische Moralreflexion ist von Anfang an auch Kritik traditioneller und konventioneller Vorstellungen vom guten und richtigen Leben. Diese philosophische Kritik betrifft sowohl konkrete Inhalte der Überlieferung wie auch die Form einer Orientierung, die hergebrachte Traditionen schon als solche für maßgebend hält. So zieht beispielsweise Heraklit aus Ephesos (ca. 520-460 v. u. Z.) traditionelle Vorstellungen von Blutrache und Ehre ins Lächerliche, indem er diejenigen, die »Reinigung « von Blutschuld suchen, »indem sie sich mit neuem Blut besudeln" mit jemandem vergleicht, »der in Kot getreten, sich mit Kot abwaschen wollte« (DK, 22B5). Heraklit bekämpft die Autorität Homers und des >Vielwissers` (DK, 22B40) Hesiod und fordert, wir sollten nicht einfach "als Kinder der Erzeuger" handeln (DK, 22B74), also nicht blind den Sitten unserer Vorfahren folgen. Orientieren sollen wir uns vielmehr an einer Vernunft, die sallen gemeinsam` ist (vgl. u. a. DK, 22B113), und naturgemäß handeln: „Gesund denken ist die größte Vollkommenheit, und die Weisheit besteht darin, die Wahrheit zu sagen und zu handeln nach der Natur, auf sie hinhörend“ (DK, 22B112). Als zentrale Orientierungsmaßstäbe treten hier, wie bei den nachfolgen-

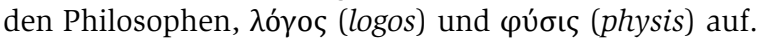


Der Begriff logos ist vieldeutig und kann sowohl ein Wort wie eine Rede(sequenz), deren Sinn, ein Argument, das Vernunftvermögen einer Person oder eine objektive Vernunft, Vernunftordnung oder vernünftige Struktur bezeichnen. In letzterer Bedeutung kann der logos dann auch als etwas verstanden werden, das die Natur ( $\varphi \dot{\sigma} \sigma ı$, , physis) durchwaltet

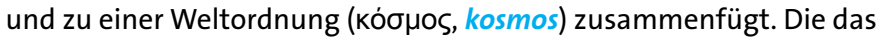
griechische Denken dominierende Vorstellung, dass die Gesamtheit der Natur sich zu einer harmonischen Ordnung zusammenfügt, kommt auch darin zum Ausdruck, dass das Wort 'kosmos` zugleich 'Schmuck, Zierrat bedeutet.

Entsprechend hat, wie Karl-Otto Apel (2011) hervorhebt, der griechische Logosbegriff einen doppelten Bezug: Entsprechend der unmittelbaren Bedeutung des Wortes logos verweist er zum einen auf die intersubjektiv geteilte Vernunft der menschlichen Rede, die sich im dialogischen Austausch von Argumenten manifestiert, zum anderen auf eine objektive, in der Natur verkörperte Vernunftordnung.

Natur und Praktische Vernunft: In den frühesten Beiträgen der griechischen Philosophie steht das Nachdenken über die Natur im Mittelpunkt. Die frühen Ansätze der milesischen Philosophie hatten das Nachdenken über die Natur zunächst aus religiösen und mythischen Zusammenhängen wie auch aus unmittelbar lebenspraktischen Kontexten herausgelöst. Spätestens seit Heraklit werden die solcherart >entmythologisierten Vorstellungen natürlicher Ordnung dann wieder als Grundlage einer traditionskritischen philosophischen Ethik herangezogen. In der als 'griechische Aufklärung bezeichneten Periode ab der zweiten Hälfte des 5. Jahrhunderts vor unserer Zeitrechnung wendet sich der Blick noch stärker auf das politische Zusammenleben. In der sich in Athen entwickelnden Demokratie lehren die Sophisten die öffentliche Rede und setzen sich in diesem Zusammenhang mit Rhetorik, Logik und Argumentationstheorie auseinander. Nicht zuletzt beschäftigen sie sich mit den zeitgenössischen Vorstellungen von Tugend und den Regeln gemeinschaftlichen Zusammenlebens. Damit reagieren sie auf einen akuten Orientierungsbedarf, der außer durch die aktuelle Erfahrung der Veränderlichkeit gesellschaftlicher Regeln durch den lebhaften Austausch mit anderen Gemeinschaften entsteht. Auch viele der in Athen lehrenden Sophisten selbst stammen ursprünglich aus fremden Poleis. Angesichts der Vielfalt unvereinbarer Gesetze, Tugendvorstellungen, religiöser Normen und Konventionen suchen sie Orientierung durch die Besinnung auf das Naturgemäße. Den

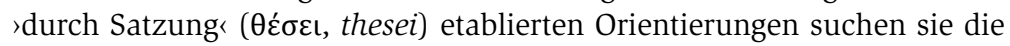
`von Natur aus` ( $\varphi$ vect, physei) geltenden Orientierungen gegenüber zu stellen, wobei mit `Natur` zumal die Natur des Menschen gemeint ist.

"Der Gegensatz von Natur und Satzung ist die am meisten charakteristische Begriffsbildung der griechischen Aufklärung; er beherrscht ihre ganze Philosophie, und er hat von vornherein [...] die Bedeutung einer Norm der Wertschätzung. Wenn es etwas Allgemeingültiges gibt, so ist es das, was "von Natur « für alle Menschen ohne Unterschied des Volkes und der Zeit gilt [...].« (Windelband 1912, S. 60) 
Trotz weitgehender Übereinstimmung in dieser Form der Begründung, sind die von den Sophisten vertretenen ethischen Vorstellungen ihrem Inhalt nach sehr verschieden.

Naturrechtsdenken der Sophisten: Protagoras (ca. 490-411 v.u.Z.) sieht sich vor dem Hintergrund einer skeptisch-relativistischen Erkenntnistheorie nicht zu radikaler Kritik bestehender Ordnungen berufen und bemüht sich, wenn wir Platons Bericht glauben dürfen, um eine Verteidigung der Demokratie. Der Sophist Alkidamas bringt »Philosophie« hingegen explizit als "Angriffswerk gegen Gesetz und Brauch" in Stellung und postuliert unter Berufung auf die menschliche Natur die Gleichberechtigung aller Menschen - »die Natur hat niemand zum Sklaven gemacht (Nestle 1908, S. 202). Die Sophisten Hippias und Antiphon teilen diese egalitaristische Auffassung; Letzterer verweist in diesem Zusammenhang auf die Gleichheit in »den natürlichen Bedürfnissen aller Menschen«:

"Sie können sie alle auf die gleiche Weise befriedigen, und in allen Dingen gibt es zwischen uns keinen Unterschied von Barbar und Grieche. Wir atmen alle die gleiche Luft durch Mund und Nase und essen alle mit den Händen."

DK, 87B44, Übers. nach Jaeger 1973, S. 413

Kallikles und Thrasymachos behaupten hingegen gerade eine natürliche Ungleichheit der Menschen und leiten daraus eine Art natürliches Recht des Stärkeren ab. Das Gerechte, so meint (Platon zufolge) Thrasymachos, sei nichts anderes als das dem Stärkeren Zuträgliche (Platon, Politeia, 338c; 344c). Kallikles zufolge wollen sich die Schwachen mit den faktisch bestehenden Gesetzen gegen diejenigen schützen, denen sie von Natur aus unterlegen wären (Platon, Gorgias, 483b) und denen sie sich natürlicherweise eigentlich unterordnen müssten (Nietzsche wird diese Auffassung später mit psychologischen Überlegungen zur Rolle des Ressentiments anreichern; Nietzsche 1988 [KSA, Bd.5]). Die Berufung auf die Natur des Menschen eignet sich offenbar zur Rechtfertigung ganz unterschiedlicher, ja entgegengesetzter Positionen.

\section{Probleme des Naturrechtsdenkens}

Hans Welzel sieht im Dissens der Sophisten über die menschliche Natur und die korrespondierenden Rechte einen frühen Hinweis auf die im naturrechtlichen Denken generell angelegte Gefahr zirkulärer (Schein-)Begründungen:

"Die Proteusgestalt der menschlichen Natur nimmt unter der Hand eines jeden naturrechtlichen Denkers die Gestalt an, die er sich wünscht. All das, was er für richtig und wünschenswert hält, hat er zuvor (stillschweigend) in seinen >Naturbegriff vom Menschen hineingelegt, ehe er es zur Begründung seiner Überzeugung von >naturgemäßく Richtigen wieder herausholt. Die `Natur des Menschen ist ein so offener und gestaltbarer Begriff, daß schlechterdings alles in ihn hineingelegt und als Begründung wieder aus ihm herausgeholt werden kann." (Weizel 1962, S. 16f.)

Zur Vertiefung 
Streben nach sicherer Erkenntnis: Sokrates, der in Platons (stilisierter) Darstellung als Überwinder des Denkens der Sophisten auftritt, sucht angesichts solcher Streitigkeiten nach demjenigen, dessen wir uns wirklich gewiss sein können. Die Methode seiner Erkundungen ist die "Mäeutik«

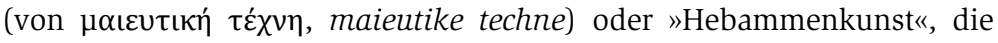
Kunst eines argumentativen Dialoges, der verdeckte Gewissheiten aufzudecken vermag:

Der neue Weg [...] des Sokrates wendet sich von der Naturphilosophie im Sinn einer unmittelbaren naiven Betrachtung der Dinge weg zu einer dialogischen Vergewisserung der Logoi. Was zur Debatte steht, sind die Leitbegriffe des Lebens, die es im Ausgang vom gemeinsam gesprochenen Wort durch schrittweise begriffliche Präzisierung und im dialogischen Rekurs auf das Einverständnis des Gesprächspartners zu rekonstruieren gilt. Die maieutische Dialogführung zielt auf gemeinsame reflexive sittliche Selbstverständigung ab, sie zwingt zur Klärung und Rechenschaftsgabe sittlicher Begriffe und Regeln, die jedermann im alltäglichen Reden und Handeln je schon einbringt. (Forschner 1995, S. 17)

In Sokrates' Streben nach sicherer Erkenntnis kommt bereits eine ethische Grundüberzeugung zum Ausdruck, die Überzeugung nämlich, dass Tugend nicht nur ein Mittel zur Realisierung vor-rationaler Neigungen ist, wie die Sophisten mehrheitlich annehmen. Tugend wird vielmehr selbst mit Einsicht identifiziert. Entsprechend nimmt Sokrates von sich in Anspruch, er habe "schon immer [...] das an mir, dass ich nichts anderem von mir gehorche, als dem logos, der sich mir bei der Untersuchung als der beste zeigt“ (Platon, Kriton, 46d). Zugleich legt eine Reihe der Sokrates zugeschriebenen Ausführungen die Auffassung nahe, dass Tugend schon für sich allein ein gutes Leben verbürgt. Demnach wäre ein gutes Leben nichts anderes als ein vernünftiges Leben, eine beständige praktische Orientierung an vernünftiger Erkenntnis. Dieser intellektualistischen Gleichsetzung eines Lebens mit einem an der Einsicht in das sittlich Gute orientierten guten Leben entspricht auch die in Platons Dialog Gorgias dem Sokrates zugeschriebene Auffassung, es sei besser, Unrecht zu leiden als Unrecht zu tun. Der besonnene Mann, der imstande sei, sein Leben in allem fromm, tapfer und gerecht zu führen, sei als solcher auch glücklich. Dies haben später auch Mitglieder der stoischen Schule behauptet. Sokrates entwickelt indes, soweit wir der Überlieferung entnehmen können, keine systematische Lehre von Recht und Unrecht oder vom guten Leben (White 2006, S. 383 ff.). Dies hilft auch zu erklären, warum von ihm beeinflusste sSchulen Kyniker und die Kyrenaiker recht unterschiedliche inhaltliche Vorstellungen vom guten Leben vertreten können.

Platons Ideenlehre: Nachhaltigeren Einfluss als die von den Vertretern dieser Schulen entwickelten spezifischen Auffassungen vom guten Leben haben die (metaphysischen, sprach- und erkenntnistheoretischen, aber werttheoretisch aufgeladenen) Überlegungen, mit denen Platon (ca. 427347 v. u. Z.) die sokratische Suche nach sicherer Erkenntnis weiter vorantreiben will. Im Dialog Eutyphron verteidigt er die Auffassung, dass das Gerechte nicht dadurch gerecht wird, weil es Gott gefällt, sondern es gefällt Gott, weil es gerecht ist. Es muss also eine objektive Grundlage für 
die Bestimmung des Gerechten geben. Platon sieht die Möglichkeit, über die Vielfalt bloßer Meinungen hinauszukommen und zu echter Erkenntnis zu gelangen, generell darin begründet, dass jenseits der wandelbaren und trügerischen sinnlichen Erscheinungswelt eine Welt intellegibler (d.h. nicht den Sinnen, wohl aber dem Intellekt zugänglicher), ewiger Ideen besteht.

Platonische Ideen Platon nimmt an, dass die sinnlich wahrnehmbaren Einzeldinge Urbildern dieser Einzeldinge nachgebildet sind, die er als Ideen bezeichnet. Diese sind zugleich vollkommener und 'wirklicher als die sinnlich wahrnehmbaren Einzeldinge. Intellektueller Zugang zu den Ideen ist die Grundlage wahrer Erkenntnis.

Zwischen den Ideen, den Gegenständen der sinnlichen Erfahrungswelt und dem erkennenden Menschen besteht dabei Platon zufolge eine Dreiecksbeziehung:

Die Dinge der Erfahrungswelt sind gleichsam Abbilder der Ideen. Insofern sie den Ideen nachgebildet sind, haben sie an den Ideen teil und sind

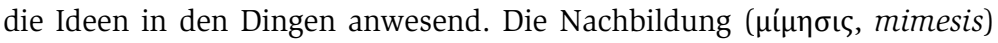
der sinnlichen Einzeldinge nach den allgemeinen Ideen, die sich daraus ergebende Teilhabe ( $\mu \varepsilon \dot{\varepsilon} \varepsilon \xi \iota \varsigma$, methexis) der Sinnendinge an den Ideen und

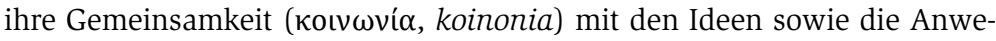
senheit ( $\pi \alpha \rho o v \sigma i ́ \alpha$, parousia) der Ideen in den Dingen bestimmen das Verhältnis zwischen Ideen und sinnlichen Gegenständen. Zugleich sollen die Ideen aber von den Einzeldingen auch getrennt ( $\chi \omega \rho$ ís, choris) bzw. abtrennbar sein (Platon, Parmenides, 130a ff.). Das Verhältnis zwischen Ideen und Einzeldingen ist überdies auch axiologisch (werttheoretisch) bestimmt, und zwar als Gefälle: Vollkommene Wirklichkeit kommt nur den Ideen zu. Die sinnlich wahrnehmbaren Einzeldinge verdanken den Ideen ihr Wesen, sie realisieren dieses Wesen aber nur in unvollkommener Weise. In erkenntnistheoretischer Hinsicht entscheidend ist nun, dass die Wesensbeziehung zwischen den allgemeinen Ideen und den ihnen nachgebildeten Gegenständen der sinnlichen Erfahrungswelt nicht nur objektiv existiert, sondern im Erkenntnisprozess gewissermaßen reproduziert werden kann. Das erkennende Subjekt kann nicht nur mittels seiner Sinne das konkrete Einzelding wahrnehmen. Vielmehr kann die Wahrnehmung des Einzeldings im erkennenden Subjekt auch die Erinnerung an die im Einzelding unvollkommen verkörperte Idee wachrufen. Diese Lehre von der möglichen Wiedererinnerung (óvó́ $\mu v \eta \sigma \iota \varsigma$, anamnesis) an die Ideen stützt Platon auf die Annahme der Seelenwanderung. Die Seele soll ihre Kenntnis von den Ideen in Zeiten nicht-körperlicher Existenz erlangt haben. Die Ideenlehre umfasst also ontologische, bedeutungstheoretische, erkenntnistheoretische und werttheoretische Annahmen. Die folgende Abbildung fasst die Zusammenhänge schematisch zusammen (siehe Abb.2.1).

Abb. 2.1:

Platons Ideenlehre

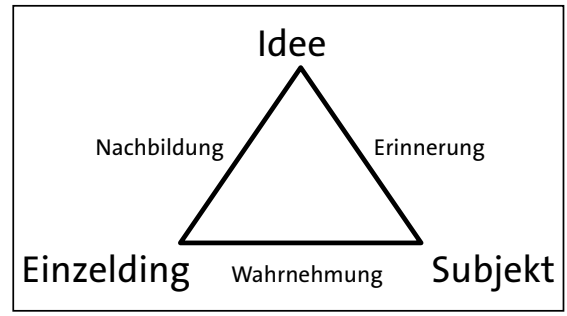


Abwertung der Sinnenwelt: Die Ideenlehre erklärt einerseits, wie korrekte Erkenntnis möglich ist: Da die Ideen die objektiven Wesensformen der Einzeldinge und zugleich die Erkenntnisformen sind, zu denen die erkennende Seele dank ihrer einstigen nicht-körperlichen Existenz intellektuellen Zugang hat und die sie daher in den Einzeldingen wiedererkennen kann, erlauben die Ideen adäquate Erkenntnis des eigentlichen Wesens der Gegenstände. Andererseits vermag die Ideenlehre auch die Entstehung der Vielfalt irriger Meinungen zu erklären: Irrtum über das wahre Wesen der Dinge ist möglich durch die mangelnde Klarheit und Vollkommenheit der sinnlichen Welt sowie einer an den sinnlichen Eindrücken orientierten Erkenntnis, die es versäumt, von der trügerischen Sinnenwelt zur Welt der Ideen fort zu schreiten. Platons Ideenlehre und der damit verknüpfte Dualismus von Sinnenwelt und Ideenwelt sind überaus folgenreich nicht nur für die Geschichte ethischen Denkens. Sie haben tiefgreifenden Einfluss auf die westliche Kulturgeschichte und das sie prägende Verständnis des Menschen von sich selbst, von seiner Seele und seiner Rolle in der Welt. Zu den Folgen gehört die relative Abwertung der Sinnenwelt gegenüber der intelligiblen Welt, die - zugespitzt durch neuplatonische Philosophen wie Plotin (205-270) und vermittelt durch Autoren wie Augustinus (354-430) - auch das christliche Weltbild nachhaltig beeinflusst.

Platons hierarchische Seelenlehre: Folgenreich ist auch Platons Seelenlehre, die unter anderem besagt, dass die Seele in drei Teile gegliedert ist, einen vernünftigen, einen >mutigen`, zu Empörung und Zorn neigenden und einen begehrenden, an sinnlicher Befriedigung orientierten. Platon versinnbildlicht die drei Seelenteile durch die Allegorie eines Wagenlenkers, der einen Zweispänner steuert, wobei der Wagenlenker für den vernünftigen Seelenteil, eines der Rösser für den mutigen und das andere für den begehrenden Seelenteil steht (Platon, Phaidros 253c ff.) Jedem der Seelenteile ordnet Platon eine spezifische Tugend $\mathrm{zu}$ : dem vernünftigen

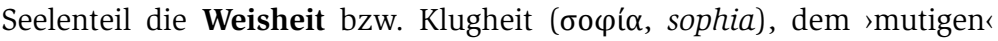
Seelenteil die Tapferkeit ( $\alpha \nu \delta \rho \varepsilon i \alpha$, andreia), und dem begehrenden die

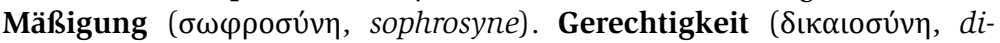
kaiosyne) sorgt als vierte Tugend dafür, die drei Seelenteile in das rechte Verhältnis zu setzen, so dass jeder die ihm zukommende Aufgabe erfüllt (u. a. Platon, Nomoi 631b f.). Diese vier von Platon in Anknüpfung an ältere Tugendkataloge aufgeführten Tugenden sind in der Patristik als Kardinaltugenden bezeichnet und in der Scholastik gemeinsam mit den aus dem Korintherbrief (1 Korinther 13) übernommenen sgöttlichen Tugenden Glaube, Liebe und Hoffnung in den Kanon der sieben Tugenden aufgenommen worden (vgl. Thomas von Aquin, Summa Theologica, II-I, q. 61 und 62).

Hierarchisches Politikideal: Platon überträgt die Vorstellung einer gerechten Ordnung der Seelenteile unter der Herrschaft der Vernunft auch auf den Staat: Da der Einfluss der verschiedenen Seelenteile bei verschiedenen Menschen unterschiedlich stark sei, manche eher von Vernunft, andere eher von Ruhmsucht oder von sinnlichen Begierden geleitet würden, sei im Staat eine ähnliche Ordnung zu etablieren wie in der Seele des Einzelnen (Platon, Politeia). Wie der vernünftige Seelenteil die übri- 
gen Seelenteile leiten und regieren muss, müssen diejenigen (`Wächter ), die zur vernünftigen Selbstherrschaft am besten befähigt sind, diejenigen regieren, die primär nach Ehre oder nach materiellen Gütern streben. Aus diesem Konzept einer natürlichen Unterschieden entsprechenden Arbeitsteilung resultiert ein hierarchisches Ideal politischer Herrschaftsorganisation, in dem Karl R. Popper (1902-1992) gar eine wesentliche Quelle totalitären politischen Denkens erblickt (Popper 2003).

\title{
2.2 | Aristoteles' Tugendethik
}

Bedeutung der Aristotelischen Ethik: Damit ist der Entstehungshintergrund der Aristotelischen Ethik skizziert, die nun im Zentrum stehen soll. Aristoteles hat der philosophischen Disziplin der Ethik ihren Namen gegeben (Ritter 1971, S. 759) und seine Nikomachische Ethik gilt nicht nur als Meilenstein der praktischen Philosophie sondern überhaupt als »einer der wirkungsreichsten Texte der Philosophiegeschichte« (Wolf 2013, S. 13).

\begin{abstract}
Aristoteles' ethische Schriften
Von Aristoteles' zahlreichen Werken ist der größte Teil verlorengegangen, darunter sämtliche Dialoge. Unter den überlieferten Texten befinden sich zwei ethische Schriften, die Eudemische Ethik und die Nikomachische Ethik, wobei Teile der beiden Schriften identisch sind. Eine dritte ethische Schrift, die sogenannte Große Ethik ist vermutlich nicht von Aristoteles selbst verfasst, dies gilt mit noch größerer Wahrscheinlichkeit auch für die Schrift Über Tugenden und Laster. Relevant für die Ethik sind unter Aristoteles' weiteren Schriften vor allem seine Werke Politik und Von der Seele. Als Ausgabe des bedeutendsten ethischen Texts, der Nikomachischen Ethik, empfiehlt sich die Neuübersetzung von Ursula Wolf (Aristoteles 2006). Sie hat auch einen konzisen Kommentar verfasst, der für ein genaueres Verständnis der Argumentation der Nikomachischen Ethik herangezogen werden kann (Wolf 2013). Der Einheitlichkeit halber werden im vorliegenden Buch jedoch alle Aristoteles-Zitate der Werkausgabe (Aristoteles 1956 ff.) entnommen, die in Bd. 6 die Dirlmeier-Übersetzung der Nikomachischen Ethik enthält. Zur allgemeinen Einführung in Aristoteles' Philosophie sind Höffe 2014 sowie Rapp/Corcilius 2021 geeignet.
\end{abstract}

Noch bemerkenswerter ist, dass nicht wenige Philosophinnen und Philosophen Aristoteles' Ethik als einen auch für die Gegenwart unmittelbar relevanten Diskussionsbeitrag begreifen (ebd., mit Verweis auf Barnes 1996, 87) oder gar sich selbst als >(Neo-)Aristoteliker` verstehen (zum Begriff vgl. Schnädelbach 1986, zur Übersicht u. a. Chappell 2006). Allerdings sind es recht unterschiedliche Motive oder Elemente der aristotelischen Ethik, Handlungstheorie, politischen Philosophie oder Sozialphilosophie, die von heutigen Autor/innen aufgegriffen werden. Im Folgen- 
den sollen zunächst die grundlegenden Eigenschaften der Aristotelischen Ethik des guten Lebens zusammentragen werden, ehe nach deren aktueller Bedeutung gefragt wird.

Aristoteles' Ursachenlehre: Wie wir gesehen haben, suchen schon die Sophisten den Streit über die gültigen moralischen Normen durch den Rückgriff auf die Natur des Menschen beizulegen, können sich aber nicht auf ein gemeinsames Verständnis dieser Natur einigen. Platons Ideenlehre verspricht zur Beilegung des Streits beizutragen, insofern sie Einsicht in die Idee des Menschen selbst ermöglicht; Einsicht in die eigentliche Wesensnatur des Menschen im Unterschied zu deren vielfältigen unvollkommenen Realisierungen. Zugleich sollen die Ideen als Wertmaßstab dienen, an dem die unvollkommene Wirklichkeit gemessen werden kann. Aristoteles lehnt zwar Platons Ideenlehre ab, knüpft im Rahmen seiner eigenen Metaphysik, Naturphilosophie und Erkenntnistheorie jedoch auch an wesentliche Elemente dieser Lehre an. Er kritisiert daran, dass das Verhältnis zwischen Ideen und den Einzeldingen - jenes Verhältnis, das Platon in Begriffen wie »Teilhabe«, "Anwesenheit« und »Gemeinsamkeit« zu erläutern sucht - letztlich doch unklar bleibe. Auch könne die Ideenlehre natürliche Entwicklungen nicht erklären. Aristoteles' Ursachenlehre soll diese Schwächen überwinden. Mit dem Begriff `Ursacher ( $\alpha i \tau^{\prime} \alpha$, aitia) bezeichnet er dabei allgemein etwas, das als Antwort auf eine >Weshalb-Frage angeführt werden kann. In entsprechenden Diskussionskontexten seien vier verschiedene Arten von Antworten anzutreffen, und entsprechend seien vier Arten von Ursachen zu unterscheiden:

\section{- Formursachen}

- Stoffursachen

- Zielursachen

\section{- Wirkursachen}

Stoffursachen bezeichnen dasjenige, woraus ein Einzelding gebildet ist. In diesem Sinne kommt beispielsweise Holz als Stoffursache eines Stuhls in Frage. Die Formursache des Stuhls ist hingegen die Gestalt des Stuhls, die das Holz allererst zum Stuhl macht, die bloße `Stuhl-Potentialität ` des Holzes also zum wirklichen Stuhl raktualisiert . Hierzu bedarf es freilich noch einer Wirkursache, etwa in Gestalt des Handwerkers, der das Holz zum Stuhl formt und dessen Tätigkeit eben gerade von der Formursache des Stuhls geleitet wird, die dergestalt zugleich den Charakter einer Zielursache annimmt.

Teleologische Naturauffassung: Entscheidend ist nun Aristoteles' Annahme, dass in den Gegenständen der Naturbetrachtung Formursache, Zielursache und Wirkursache regelmäßig zusammenfallen (u. a. Aristoteles Physik, 198a): So ist für die Kastanie die Form des ausgewachsenen und gesunden Kastanienbaums zugleich das Ziel ihrer Entwicklung und die treibende Wirkursache, welche die Entwicklung vom Sprössling zum ausgewachsenen Baum erklärt. 


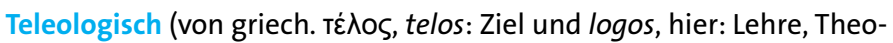

rie) werden unterschiedliche Dinge genannt:

1. In der Naturphilosophie wird als steleologischr eine Auffassung von der Natur bezeichnet, der zufolge natürliche Entwicklungen als zielgerichtete Prozesse verstanden werden, d. h. im direkten Rekurs auf Entwicklungsziele auch kausal erklärt werden können (klassisch: Aristoteles' Naturphilosophie).

2. In der Moralphilosophie bezeichnet der Begriff - gemäß der Standarddefinition von William K. Frankena (1973, S. 14 f.) und John Rawls (1975, S. 48 ff.) - eine Position normativer Ethik, die das moralisch Richtige mit demjenigen gleichsetzt, das ein vor-moralisches Gut maximiert (klassisches Beispiel: Benthams Handlungsutilitarismus). Alle nicht-teleologischen normativen Ethiken werden als deontologisch bezeichnet; Deontologie und Teleologie werden als kontradiktorische Begriffe verstanden (als Überblick über alternative Definitionen vgl. Gaus 2001).

Dieselbe Konstellation soll auch für die gesetzmäßigen Bewegungen der anderen veränderlichen Naturdinge wesentlich sein. Sie tragen jeweils eine bestimmte Gestalt ihrer selbst als intrinsisches Entwicklungsziel in sich und streben nach dessen (möglichst vollkommener) Realisierung.

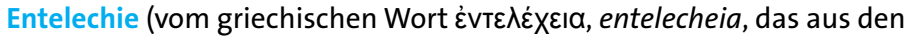

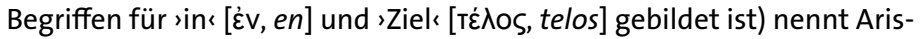
toteles ein den Naturdingen jeweils innewohnendes Entwicklungsziel, das sowohl deren ideale Wesensform und reigentliche Natur bezeichnen als auch deren Entwicklung in Richtung dieser Wesensform (z. B. die Entwicklung des Kastaniensprösslings zum ausgewachsenen Kastanienbaum) kausal erklären soll.

Die Annahme, dass den Naturdingen ideale Wesensformen innewohnen, teilt wesentliche Züge mit Platons Ideenlehre: Wie die Ideen die Einzeldinge zugleich als Dinge einer bestimmten Art bestimmen und das im Vergleich zu den Einzeldingen Bessere darstellen, so repräsentieren auch die aristotelischen Wesensformen zugleich das eigentliche Wesen wie auch die vollkommene Realisierung der Einzeldinge. Anders als Platon die von ihm postulierten Ideen, betrachtet Aristoteles die Formen allerdings nicht als von den Einzeldingen abtrennbar (Aristoteles, Metaphysik, 1086b9). Zudem erklären die inhärenten Wesensformen als $>$ Entelechien der Naturdinge zugleich deren Entwicklung. Alle sich bewegenden Dinge - die vergänglichen der sublunaren Welt wie die ewigen Himmelskörper - sind ihm zufolge in eine Naturordnung eingebunden, die von einem letzten Ziel, dem sunbewegten Beweger`, in Gang gehalten wird, nach dem alles strebt. In diesem Sinne vertritt Aristoteles eine teleologische Naturauffassung. 


\section{Teleologische versus evolutionstheoretische Erklärung}

Aristoteles stellt sich in Buch II der Physik durchaus die Frage, ob wir statt der von ihm selbst vertretenen teleologischen Naturauffassung (wonach alle veränderlichen Naturdinge nach einem Zweck streben) nicht ebenso gut annehmen könnten, dass alle naturhaften Veränderungen völlig zweckfrei, lediglich aufgrund kausaler Notwendigkeit erfolgen. Könnten wir, so fragt er, nicht beispielsweise annehmen, dass es nur regnet, weil sich feuchte Luft beim Aufsteigen abkühlt, wodurch die Feuchtigkeit kondensiert und schließlich abregnet (statt vielmehr anzunehmen, dass es regnet, damit das Getreide auf dem Acker gedeiht)? Könnten wir uns, fährt Aristoteles fort, nicht sogar vorstellen, dass auch die im Sinne der Bissfunktion so beeindruckend zweckmäßige Anlage des Gebisses - mit scharfen, zum Abbeißen geeigneten Zähnen in der Front und flachen, zum Zermalmen geeigneten, weiter hinten - lediglich durch Zufall zustande gekommen ist, sowie dadurch, dass dysfunktionale Kieferbildungen ausgestorben sind? Interessanterweise spekuliert Aristoteles an dieser Stelle über die Möglichkeit evolutionstheoretischer Erklärungen (durch szufällige Variation und Selektion) für funktional organisierte biologische Strukturen - Erklärungen ungefähr der Art, wie sie im 19. Jahrhundert Charles Darwin entwickelt hat. Aristoteles belässt es dann aber bei einem hypothetischen Gedankenexperiment, das er im Anschluss (auf weniger überzeugende Weise) zu widerlegen versucht. Erklärungen durch `zufällige` Variation und Selektion könnten die allgemeine Ordnung und Regelmäßigkeit natürlicher Prozesse letztlich doch nicht erklären (vgl. Aristoteles, Physik, 198b ff.).

Seele als

Entelechie eines Lebewesens
Seelenlehre als Grundlage der Ethik: Anknüpfung an und Abgrenzung von Platons Philosophie prägt auch Aristoteles' Vorstellung von der Seele, die er auf Grundlage der soeben skizzierten Naturauffassung entwickelt. Die Seele ist ihm zufolge als Entelechie eines lebenden Wesens zu verstehen, sie verhält sich also zu sihrem` Körper wie die Form-, Ziel- und Wirkursache zur Materie (Aristoteles, Über die Seele, 415b). Anders als Platon betrachtet Aristoteles die Seele daher auch nicht als vom Körper abtrennbar (abgesehen von einer gewissen Unklarheit bezüglich des vernünftigen Seelenvermögens). Als >erste Aktualität dieses Körpers ist die Seele vielmehr dasjenige, was dem nur potentiell lebendigen Körper tatsächlich Leben verleiht. Beseeltheit unterscheidet mithin die belebte Natur (einschließlich der Pflanzen) von der unbelebten Natur. Aristoteles postuliert ferner eine Stufenordnung von Potentialitäten und ihren jeweiligen Aktualisierungen: Die Aktualisierung einer Potentialität kann zugleich die Potentialität für eine weitere, darauf aufbauende Aktualisierung darstellen. Dies trifft auch auf die Seele zu: Als erste Aktualität eines potentiell lebendigen Körpers ist die Seele zugleich die Potentialität weiterer Tätigkeiten, die ihrerseits als Aktualisierung entsprechender Seelenvermögen verstanden werden können. Dabei besitzen Pflanzen, Tiere und Menschen, entsprechend ihren unterschiedlichen Lebensäußerungen, unterschiedlich komplexe Seelenvermögen, wobei die shöheren weils `niedrigeren` Vermögen in Form einer Art Stufenordnung voraus- 
setzen: Den Pflanzen eignet ein vegetatives Seelenvermögen, das ledig-

Menschliche Seelenvermögen ein für sie typisches animalisches Seelenvermögen hinzu, das für Sinneswahrnehmungen, basale Bewertungen und Strebungen sowie für Ortsbewegungen zuständig ist. Die menschliche Seele umfasst als Einzige zusätzlich zu den beiden vorgenannten ein rationales Seelenvermögen, das zu Einsicht und vernünftigem Handeln befähigt. Der Ausflug in die Naturphilosophie und Seelenlehre war notwendig, weil Aristoteles in seiner Handlungstheorie, Ethik und politischen Philosophie daran anknüpft: Wie alle übrigen Naturwesen strebt auch der Mensch nach der Aktualisierung seiner natürlichen Wesensform. Im Licht dieser aristotelischen Auffassung ist der von Pindar stammende Leitspruch »Werde, der du bist!« so zu interpretieren, dass wir die vollkommene Realisierung derjenigen Wesensform anstreben sollen, die für unsere allgemeine Menschennatur charakteristisch ist. Insofern ist unsere Aufgabe als Menschen anscheinend vergleichbar mit derjenigen des Kastaniensprösslings, dem durch seine natürliche Anlage saufgegeben ist`, ein ausgewachsener, gesunder Kastanienbaum zu werden. Für Kastaniensetzlinge wie für Menschen legt das für sie spezifische Entwicklungsziel zugleich fest, was für sie gut ist: Gut ist ihr natürliches Wesensziel selbst und entsprechend auch dasjenige, was zu dessen Verwirklichung beiträgt; schlecht ist, was die Realisierung dieses Ziels hemmt oder vereitelt.

Selbstentfaltung der Wesensnatur: Wenn wir heutzutage für einen als positiv bewerteten persönlichen Entwicklungsprozess den Begriff `Selbstentfaltung verwenden, schwingen solche essentialistisch-naturteleologischen Konnotationen immer noch mit. Auch diese Redeweise legt ja eine natürliche Entwicklung ähnlich der eines Samenkorns oder Keimlings nahe, der den Bauplan der ausgewachsenen Pflanze in sich trägt. Andererseits ist unser gegenwärtiger Begriff der Selbstentfaltung von einem Individualismus geprägt, der sich erst in der Neuzeit durchzusetzen beginnt und dort gerade gegen wesentliche Züge der aristotelischen Metaphysik zur Geltung gebracht wird. Das moderne Konzept der Selbstentfaltung zielt auf die freie Entwicklung eines unvertretbaren Individuums, dessen Wert gerade an seiner einmaligen Individualität haftet. Aristoteles' Ethik zielt hingegen auf die Entfaltung einer allgemeinen menschlichen Wesensnatur, die prinzipiell für alle Menschen dieselbe ist. Da, wie wir gesehen haben, die menschliche Seele als Form des menschlichen Körpers dessen eigentliche Wesensnatur zum Ausdruck bringt, bestimmt Aristoteles in seiner Ethik das für den Menschen spezifische Gut in der Aktualisierung der Wesensnatur der menschlichen Seele.

Glück als Tätigkeit der Seele: Da wiederum das Vernunftvermögen dasjenige Seelenvermögen darstellt, das für die Seele des Menschen im Unterschied zu allen anderen Arten spezifisch ist, besteht das höchste Gut für den Menschen in der Aktualisierung des Vernunftvermögens, das heißt in der Tätigkeit der Seele gemäß ihrer spezifischen >Vollkom-

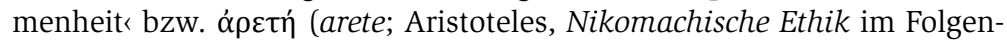
den NE, 1098a, 1102a; wenn nicht anders angegeben, stammen alle nachfolgenden Aristoteles-Zitate aus derselben Schrift). Diese Tätigkeit iden-
Antikes vs. neuzeitliches Konzept von Selbstentfaltung 


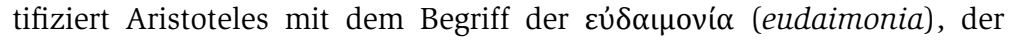
meist mit `Glück` oder `Glückseligkeit` übersetzt wird.

Eigenständige ethische

\section{Tugend und Vollkommenheit}

Aristoteles' Ethik wird häufig als >Tugendethikı bezeichnet. Treffend erscheint das dann, wenn man `Tugend im Sinne des von Aristoteles ver-

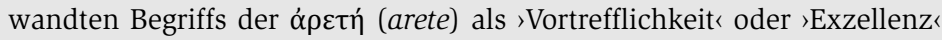
versteht, nicht aber im Sinne einer moralisch vorbildlichen Haltung oder gar im Sinne eines überspannten Moralismus, wie er beispielsweise in dem ironisch-abschätzigen Ausdruck `Tugendbold` begegnet. Anders als der antike Begriff der arete setzt der manchmal auf moralische Vorbildlichkeit zugespitzte moderne Tugendbegriff bereits eine Differenzierung zwischen moralischen Fragen des Richtigen und Gerechten einerseits und Fragen des individuellen oder gemeinschaftlichen guten Lebens andererseits voraus. Diese Differenzierung ist in der Aristotelischen Ethik aber höchstens in Ansätzen zu finden (etwa in der Gerechtigkeitslehre und Bemerkungen zum Schicklichen); sie spielt noch keine tragende systematische Rolle. Etymologisch stammt der deutsche Begriff `Tugend übrigens vom Wort staugen<. Wenn man Tugend entsprechend ganz allgemein als vorbildliche 'Tauglichkeit` in Beziehung auf ein bestimmtes Ziel versteht, kommt dies dem Aristotelischen Tugendverständnis durchaus nahe.

Ausgehend von Aristoteles' Naturphilosophie sind wir damit zu einer Kernaussage der aristotelischen Ethik gelangt: Glück ist eine Tätigkeit der Seele, und zwar die Tätigkeit gemäß der ihr eigentümlichen Vollkommenheit; eine Tätigkeit, in der sie die für sie spezifischen Vermögen in vorzüglicher Weise realisiert.

Reflexion auf die menschliche Lebenspraxis: Die Nikomachische Ethik könnte nach der bisherigen Darstellung als bloßes `Anhängsel der Naturphilosophie erscheinen. Dies wäre jedoch ein Missverständnis. Denn erstens führt sie jene Kernaussage nicht einfach als Resultat der Naturphilosophie ein, sondern entwickelt sie vielmehr auf dem Wege der Prüfung alternativer Vorstellungen vom guten Leben. Zweitens sucht sie diese Kernaussage in einer Weise zu präzisieren, die nicht vollständig aus naturphilosophischen Überlegungen abzuleiten ist, sondern sich der Reflexion auf die menschliche Lebenspraxis verdankt. Drittens bereichert sie die Diskussion der praktischen Philosophie mit zahlreichen weiteren handlungstheoretischen und ethischen Überlegungen, die eine unabhängige Bedeutung und Begründungsbasis haben.

Praxis und Poiesis: Aristoteles geht von der Annahme aus, dass alle Tätigkeiten und Verrichtungen auf ein Gut zielen, um dessen Realisierung willen sie unternommen werden. Einige Tätigkeiten zielen auf die Realisierung eines externen Gutes. So arbeitet der Handwerker, der einen Tisch konstruiert, eben um des erhofften Resultats seiner Arbeit willen, des fertigen Tisches. Andere Tätigkeiten tragen ihr Ziel hingegen in sich. So mag es einem Spaziergänger nicht darum gehen, zu einem bestimmten Ort zu gelangen, sondern um den Spaziergang an sich. Tätigkeiten, 
die auf die Realisierung eines externen Ziels gerichtet sind, bezeichnet

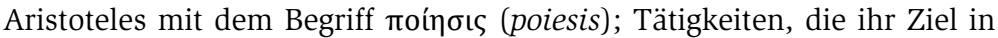
sich tragen, nennt er $\pi \rho \tilde{\alpha} \xi ı s$ (praxis).

Hierarchie von Zielen: Da es immer die Ziele sind, um derentwillen Mittel gebraucht werden, sind sie grundsätzlich wertvoller als die jeweiligen Mittel. Freilich kann die Realisierung eines Mittels, das der Realisierung eines bestimmten Ziels $\left(Z_{1}\right)$ dient, selbst zum Ziel $\left(Z_{2}\right)$ einer Tätigkeit werden. So kann es nötig sein, zunächst ein Werkzeug zu produzieren, bevor mit Hilfe des Werkzeugs die Konstruktion eines Tisches angegangen werden kann. Es handelt sich dann beim verfolgten Ziel $\left(Z_{2}\right)$ eben nicht um ein Endziel, sondern um ein Teilziel, dessen Wert lediglich instrumenteller Natur und vom Wert des grundlegenden Ziels $\left(\mathrm{Z}_{1}\right)$ abgeleitet ist. Ausgehend von der Annahme, dass Ziele den jeweils zu ihrer Realisierung gewählten Mitteln gegenüber wertvoller sind, kommt Aristoteles zu der Auffassung, dass Tätigkeiten, die die Form der praxis haben, also ihr Ziel in sich selbst tragen, grundsätzlich wertvoller sind als Tätigkeiten poietischen Charakters, denen lediglich ein instrumenteller Wert im Hinblick auf Ziele zukommt, denen die Handlung selbst äußerlich ist. Ferner folgert er, dass dasjenige Ziel, das wir ausschließlich um seiner selbst willen anstreben und niemals um eines anderes Ziel willen wählen, das wertvollste aller Ziele darstellt:

"Wenn es nun wirklich für die verschiedenen Formen des Handelns ein Endziel gibt, das wir um seiner selbst willen erstreben, während das übrige nur in Richtung auf dieses Endziel gewollt wird, und wir nicht jede Wahl im Hinblick auf eine weiteres Ziel treffen - das gibt nämlich ein Schreiten ins Endlose, somit ein leeres und sinnloses Streben -, dann ist offenbar dieses Endziel idas Gutı und zwar das oberste Gut."

Glück als Endziel allen Strebens: Die Aufgabe der ethischen Untersuchung besteht nun wesentlich in der Klärung der Frage, worin dieses »Endziel« und »oberste Gut« genau besteht. Ganz wie ein Vertreter der modernen Sprachphilosophie geht Aristoteles zunächst vom allgemeinen Sprachgebrauch aus. Er stellt fest, dass Glück ( $\varepsilon \dot{\delta} \delta \alpha \mu$ oví $\alpha$, eudaimonia) gemeinhin als jenes Endziel genannt werde, das niemals um eines anderen Zieles willen, sondern stets um seiner selbst willen erstrebt wird und um dessentwillen alles andere angestrebt wird (1095a14 ff.; vgl. 1097a23 ff.).

\section{Von dämonischen Kräften zum autonomen Gewissen}

Dass Aristoteles gerade den Begriff der eudaimonia als Synonym für das höchste Gut des Menschen wählt, ist (angesichts möglicher Alternativen; vgl. Gigon 2006, S. 96 ff.) alles andere als trivial. In dem Begriff steckt der griechische Ausdruck für ’gut‘ ( $\varepsilon \tilde{v}, e u$ ) sowie das Wort $\delta \alpha i ́ \mu \omega v$ (daimon). Der Wandel des Begriffs daimon ist kulturgeschichtlich aufschlussreich. Gebraucht etwa Homer den Begriff zur Kennzeichnung von Göttern oder unsichtbaren Wesen (>Dämonen ‘), die von außen Einfluss auf das Schicksal der Menschen ausüben - Menschen, die sich "selbst«, wie Bruno Snell zu zeigen gesucht hat, noch nicht als selbständige Individuen, son-

Ziele und Mittel

Aristoteles, NE, 1094a18 ff.

Glück als höchstes Gut 
dern »als Schauplatz willkürlicher und unheimlicher Gewalten fühlen« (Snell 1948, S. 36) - so erklärt schon Heraklit pointiert, für den Menschen sei sein eigener Charakter sein daimon (DK, 22B119). Sokrates spricht

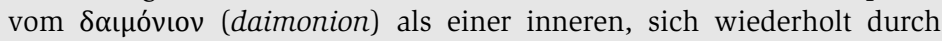
Warnungen vernehmbar machenden Stimme. In der heutigen Interpretation wird Sokrates' Rede vom daimonion regelmäßig als Bezugnahme auf das menschliche Gewissen verstanden, während sie bei Sokrates' Zeitgenossen den gefährlichen Verdacht nährt, Sokrates wolle neue Götter an die Stelle der alten setzen, der schließlich auch zu Sokrates' Verurteilung führt. Wenn Aristoteles mit großer Selbstverständlichkeit die eudaimonia als Angelegenheit des menschlichen Handelns und der praktischen Vernunft beschreibt, so lässt sich dies vor dem Hintergrund dieser Begriffsgeschichte als Hinweis auf einen Prozess der Verinnerlichung und Rationalisierung deuten; plakativ gesagt: auf einen Prozess, der von einem (vergleichsweise) heteronomen zu einem (vergleichsweise) autonomen menschlichen Selbstverständnis geführt hat. Wo die stoischen Philosophen (und in abgeschwächter Weise schon Aristoteles) Autarkie zum Merkmal eines glückenden Lebens erheben, scheinen sie die Unabhängigkeit des sguten Daimon` von äußeren Zufällen sogar geradezu in den Rang einer analytischen Wahrheit zu erheben: nur ein unabhängiger >Daimon` kann überhaupt als 'gut bezeichnet werden.

Prüfung verbreiteter Annahmen
Die wahre Natur des Glücks: Damit ist jedoch noch keine inhaltliche Vorentscheidung getroffen. Auch hinsichtlich der Frage, wie dieses `Glück genannte höchste Gut inhaltlich genauer zu bestimmen ist, beginnt Aristoteles seine Untersuchung, indem er zunächst landläufige Auffassungen über das Glück versammelt. Allerdings zeichnet sich hier kein Konsens ab. Also müssen die möglichen Auffassungen im Hinblick auf ihre Haltbarkeit untersucht werden. Diese Untersuchung - die Klärung der Frage, wie die wahre Natur des Glücks zu bestimmen ist - fällt Aristoteles zufolge in die Zuständigkeit der politischen Wissenschaft, der Wissenschaft vom Gemeinwesen. Zwar sei das Gute für den Einzelnen identisch mit dem Guten für das Gemeinwesen, meint Aristoteles, der als Vertreter eines organismischen Politikmodells davon ausgeht, dass Menschen von Natur aus nach einer Gemeinschaft streben, die eine harmonische Integration der individuellen Einzelziele in ein Staatsziel ermöglicht. Vollkommener als ein gutes Einzelleben sei jedoch das gute Leben der gesamten Gemeinschaft (1094b6 ff.).

Begrenzte Präzision ethischen Wissens: Die Zuständigkeit der politischen Wissenschaft schließt freilich nicht aus, dass Aristoteles für die Beantwortung der Frage nach der Natur des Glücks auch Erkenntnisse der Naturphilosophie und insbesondere der Seelenlehre nutzbar machen will, ebenso wie schon Platon in seiner politischen Theorie auf seine Lehre der drei Seelenteile zurückgegriffen hat. Aristoteles warnt allerdings sogleich vor überzogenen Erwartungen hinsichtlich ethischer Untersuchungen: Angesichts der Unbeständigkeit der menschlichen Lebensbedingungen dürfe man von ihr nicht dieselbe Präzision erwarten wie etwa von der Mathematik. Allgemeinaussagen über die menschliche 
Lebenspraxis könnten nur grundsätzlicher Art sein und das ethisch Richtige nur in groben Umrissen angeben. Entsprechend der Abhängigkeit ethischer Überlegungen von der faktischen Lebenspraxis sei eine auf Lebenserfahrung gründende Urteilskraft nötig, um die sumrisshaften ethischen Allgemeinaussagen angemessen interpretieren zu können (1094b12 ff.).

Glück als Tätigkeit der Seele: Aristoteles zufolge sind vor allem drei landläufige Auffassungen über die Natur des Glücks anzutreffen, denen drei Formen der Lebensführung entsprechen. Die erste identifiziert Glück mit Genuss, die zweite identifiziert es mit Ehre und gesellschaftlicher Anerkennung, die dritte mit der Tugend oder, genauer gesagt, der Ausübung der Tugend. Aristoteles schließt sich (einer spezifischen Form) der dritten Auffassung an. Wie wir bereits gesehen haben, begreift er Glück als Tätigkeit der Seele, genauer gesagt, die Tätigkeit der Seele gemäß der für sie spezifischen Befähigung (1098a15 ff.). Wie aber begründet er diese Parteinahme? Welche Kriterien legt er an die möglichen Auffassungen über die beste Lebensform an, um zu einer vernünftigen Entscheidung zu kommen? Charakteristisch für Aristoteles' ethische Argumentation und überhaupt für seine Art zu denken ist, dass er sozusagen nicht alles auf eine Karte setzt, sondern für seine Position eine Reihe von Kriterien und Gründen anführt, von denen hier nur die wichtigsten genannt sein sollen.

Naturgemäßheit: Eines der Kriterien - vielleicht das insgesamt gewichtigste - kennen wir bereits. Es ist das von fast allen antiken Ethiken herangezogene Kriterium der Naturgemäßheit, das in Aristoteles' Fall die spezifische Form des sogenannten Ergon-Arguments annimmt (von griech. है $\rho \gamma o v$, ergon: Werk). Da das für die menschliche Seele spezifische "Werk", ihre spezifische Potentialität im Unterschied zu allen übrigen Tieren, im Vernunftvermögen liegt, ist das beste menschliche Leben eines, in dem dieses Vermögen so vollkommen wie möglich aktualisiert wird, also idealerweise ein der vernünftigen Reflexion und theoretischen Kontemplation gewidmetes Leben.

Plausibilität: Ein weiteres Kriterium drückt Aristoteles durch die Methode seiner Untersuchung aus, die Tatsache nämlich, dass er in seiner Untersuchung von landläufigen Auffassungen ausgeht und seine eigene Position immer wieder mit diesen Auffassungen abzugleichen bestrebt ist. Aristoteles argumentiert nicht als erkenntnistheoretischer Solipsist, der über einen sicheren Weg zur Wahrheit zu verfügen meint, sondern als Gesprächspartner, der seine vernünftigen Zeitgenossen zu überzeugen hofft.

\section{Solipsismus und Egoismus}

Der Begriff `Solipsismus` (gebildet durch Zusammenziehung aus lat. solus, sallein ‘ und ipse, sselbst`) wird heutzutage zur Charakterisierung erkenntnistheoretischer Positionen verwandt, etwa der Auffassung, dass das Wissen von eigenen Bewusstseinsinhalten gegenüber anderen Formen von Wissen privilegiert sei, oder der Auffassung, dass ein Subjekt prinzipiell ohne Kommunikation mit anderen Subjekten zu Erkenntnis-

Urteilskraft

Glück als vollkommene Seelentätigkeit 
sen kommen könnte. Bis ins 19. Jahrhundert bezeichnete der Begriff hingegen die ethische Auffassung, wonach den eigenen Bedürfnissen und Interessen Vorrang vor den Bedürfnissen und Interessen Anderer zukommt. Diese ethische Auffassung würden wir heute als `Egoismus zeichnen; die frühere Terminologie war "genau umgekehrt« (Gabriel 1972 ff., Sp. 1018).

Es lassen sich in der Nikomachischen Ethik auch Ansätze zu einer Konsenstheorie der Wahrheit erkennen (vgl. 1173al ff.). Indes vertritt Aristoteles ersichtlich keine Common-Sense-Theorie, die allen Zeitgenossen dieselbe Urteilskompetenz zusprechen würde.

\section{Common-sense-Theorien und Konsenstheorien}

Common-Sense-Theorien schreiben Einschätzungen, die weithin geteilt werden, eine erhöhte Wahrscheinlichkeit zu und halten es deshalb (und gegebenenfalls noch aus weiteren Gründen) für geboten, bei der Bildung (moral)philosophischer Theorien vom allgemeinen ('gesunden`) Menschenverstand oder dem `Gemeinsinn (common sense) auszugehen. In der stoischen Naturrechtstradition wird die Berufung auf den consensus gentium, die Übereinstimmung zwischen den Völkern, vielfach als eines der wesentlichen Kriterien des ethisch Richtigen anerkannt. Noch weiter gehen allgemeine Konsenstheorien der Wahrheit, die Konsens nicht nur als ein starkes Indiz für Wahrheit verstehen, sondern den Wahrheitsbegriff selbst unter Bezugnahme auf das Konzept eines sidealen Konsenses zu explizieren suchen, (wobei die Kriterien für rideale Konsense in den verschiedenen Konsenstheorien jeweils unterschiedlich gefasst werden).

Vielmehr argumentiert er im Kontext von Traditionen und konventionellen Vorstellungen, die ihrerseits von aristokratischen Idealen geprägt sind. Deshalb gilt ihm der Umstand, dass die Gleichsetzung von Glück mit sinnlichem Genuss von >Vielen ment für diese Auffassung (Aristoteles, NE, 1095b). Wie Platon geht er davon aus, dass sich Menschen bezüglich ihrer natürlichen Vernunftanlagen unterscheiden. Das führt ihn - während Sophisten wie Alkidamas schon gegen die Institution der Sklaverei argumentieren - auch zu der Auffassung, dass es "Sklaven von Natur« (Aristoteles, Politik, 1254a) gebe. Für diejenigen, die nicht imstande sind, ihr Leben der Führung ihrer Vernunft zu unterwerfen, sei es besser, durch einen vernünftigen Herrn geleitet zu werden, als unbeherrscht ihren Leidenschaften ausgeliefert zu sein (s. Kap. 9.5.1). Daneben seien die bereits erwähnten Unterschiede im Maß an Lebenserfahrung in Rechnung zu stellen, die für ethische Urteilsfähigkeit notwendig seien. Junge Menschen, denen es an Erfahrung fehlt, kommen Aristoteles zufolge prinzipiell nicht als ethische Ratgeber in Frage.

Konsistenz: Ein weiteres Kriterium wird von Aristoteles in vielfältiger Weise angewandt, indem er gängige Auffassungen im Hinblick auf ihre interne Stimmigkeit befragt. So hält er eine primär dem Gelderwerb ge- 
widmete Lebensform für indiskutabel, weil sie mit dem Reichtum etwas als letztes Ziel des menschlichen Handelns ansetzt, das selbst lediglich instrumentellen Charakter hat. Reichtum leitet seinen Wert ja zur Gänze von den dadurch zu gewinnenden Gütern ab (1096a6ff.). Auch Ehre könne nicht als letztes Ziel des Lebens verstanden werden. Denn ob einem Akteur von anderen Menschen Ehre erwiesen wird oder nicht, hänge primär von den mehr oder weniger überzeugenden Entscheidungen der Ehrenden und nur sekundär vom Verhalten des Geehrten ab. Das widerspreche aber der Annahme, dass das Gute für einen Menschen etwas sein müsse, das wesentlich ihm gehöre und ihm nicht leicht genommen werden könnte.

Autarkieideal: Die letztgenannte Überlegung bringt noch eine weitere wesentliche Annahme zum Ausdruck: Vollkommenheit geht gepaart mit Unabhängigkeit von äußeren Umständen, mit Selbstgenügsamkeit (1097b7 ff.). Diese Wertschätzung der Autarkie hat sich schon in der Hochschätzung der Praxis angedeutet, die ja im Vergleich zur Poiesis insofern selbstgenügsamer ist, als sie ihr Ziel in sich trägt, und die eben darum auch wertvoller ist als die instrumentellen Verrichtungen, die Aristoteles Poiesis nennt. Für eine möglichst autarke Lebensweise spricht aber vor allem, dass das Gelingen des eigenen Lebensentwurfs dadurch weniger den Wechselfällen des Schicksals ausgesetzt wird, also eher Dauer verspricht. Indem Aristoteles menschliches Glück mit einer vollkommenen (tugendhaften) Tätigkeit der menschlichen Seele identifiziert, sieht er uns sehr weitgehend selbst als `unseres eigenen Glückes Schmied . Allerdings geht er in dieser Auffassung nicht so weit wie später die Philosophen der Stoa. Vollständig realisiert ist das Ideal der Selbstgenügsamkeit nur im sunbewegten Beweger . Entsprechend kann ein tugendhafter Mensch zwar niemals ganz unglücklich werden; zum vollen Glück bleibt er aber doch auf äußere Umstände angewiesen, die nicht vollständig in seiner Macht liegen. Wer etwa vereinsamt oder umgeben von falschen Freunden, kinderlos oder ohne alle Mittel lebt, kann nicht vollkommen glücklich genannt werden (1099a34 ff.). Gutes Leben bedeutet stets auch gutes Zusammenleben in einer wohlgeordneten Gemeinschaft.

Wesen und Formen der Tugend: In abstrakter Form ist damit das menschliche Glück definiert, nämlich als seelische Tätigkeit gemäß der vollkommenen Tugend, ausgestattet mit den nötigen äußeren Gütern über den Verlauf des gesamten Lebens hinweg (1101a14ff.). Was ein tugendhaftes Leben auszeichnet, bedarf jedoch noch genauerer Klärung. Das vernünftige Seelenvermögen kann zunächst in zweierlei Weise aktualisiert werden: zum einen, indem es seiner ihm allein zufallenden Aufgabe, der Erkenntnis, nachkommt, zum anderen, indem es sich zum ranimalischen seelenteil verhält und die dort angesiedelten Leidenschaften reguliert. Entsprechend unterscheidet Aristoteles zwischen intellektuellen Tugenden wie der Auffassungsgabe oder Klugheit und ethischen Tugenden wie beispielsweise der Besonnenheit oder Großzügigkeit (1103a3 ff.). Aristoteles setzt die ethische Tugend nicht mit Erkenntnis gleich. Er versteht sie vielmehr als eine Haltung, die das Verhältnis zwischen dem Vernunftvermögen und dem a-rationalen Strebevermögen der menschlichen Seele bestimmt. Freilich ist dieses Verhältnis so beschaf-

Intellektuelle und ethische Tugenden 
fen, dass der Vernunft die Leitungsfunktion zukommt. Ethische Tugend besteht aber eben nicht nur darin, den richtigen Weg zu erkennen, sondern auch darin, ihn zuverlässig und aus den adäquaten Gründen zu gehen. Hierzu ist neben Einsicht auch Erziehung und Einübung nötig, die das der rechten Einsicht Gemäße für den Tugendhaften auch zum Angenehmen macht (1103a23 ff., 1104b24 ff.).

Mesotes-Lehre: Wie aber findet der Tugendhafte den rechten Weg? Aristoteles interpretiert diesen Weg wesentlich als Mittelweg zwischen zwei Extremen. So wie in der Ernährung die gesunde Mitte zwischen Mangel und Übermaß einzuhalten ist, so ist bezüglich aller Leidenschaften die rechte Mitte zu suchen (1104a11 ff.).

Definition

Mesotes-Lehre nennt man die von Aristoteles vertretene Auffassung, wonach die ethischen Tugenden jeweils ein Mittleres darstellen, das zwischen gegensätzlichen Extremen angesiedelt ist (die sog. goldene Mitte).

So bildet Tapferkeit die Mitte zwischen leichtfertiger Tollkühnheit und Mitte" Feigheit; Besonnenheit die Mitte zwischen Zügellosigkeit und stumpfer Indifferenz (ebd.), Großzügigkeit die Mitte zwischen Geiz und Verschwendungssucht, Schamhaftigkeit die Mitte zwischen Schamlosigkeit und Schüchternheit. Heutzutage noch gebräuchliche Redeweisen wie die von der sgoldenen Mitte zeugen vielleicht nicht allein vom bleibenden Einfluss der aristotelischen Ethik, sondern auch von einer gewissen Plausibilität dieses Grundgedankens. Allerdings macht schon Aristoteles selbst auf Schwierigkeiten aufmerksam (1107a7ff.). In manchen Fällen wirken die Gruppierungen künstlich, mitunter fehlen einzelne Glieder in der Dreiheit der Begriffe. Vor allem stellt sich im Hinblick auf manche Tugenden die Frage, ob sie überhaupt als Mitte zwischen Extremen zu interpretieren sind. Ist Wahrhaftigkeit tatsächlich die Mitte zwischen Unverschämtheit und Ironie (1108a19ff.) und bezeichnet sie überhaupt einen Mittelweg? Auch die Tugend der Gerechtigkeit wirft Fragen auf; nicht so sehr, weil man sie nicht mit einer Mitte zwischen einem Zuviel und Zuwenig in Verbindung bringen könnte, sondern weil nicht ersichtlich ist, inwiefern sie die Mitte zwischen zwei Leidenschaften bezeichnet.

Ethische Autorität und Konformismus: Eine weitere Schwierigkeit liegt in dem Umstand, dass die Mitte zwischen extremen Haltungen, anders als die Mitte zwischen den beiden Grenzen einer Straße, weder eindeutig markiert noch durch irgendein exaktes Messverfahren zu berechnen ist; es gibt keine Geometrie der Leidenschaften. Aristoteles zufolge sollen wir uns daher an den Einschätzungen verständiger Personen orientieren (1106b35 f.). Diese Auskunft hat die Frage provoziert, ob Aristoteles sich nicht eines Zirkelschlusses schuldig mache (z. B. Tugendhat 1993, S. 252). Christian Illies formuliert das Problem zugespitzt so: 
»Grob gesagt scheint Aristoteles wie folgt zu argumentieren: Eine Tugend ist eine Disposition, die Mitte zwischen zwei Extremen zu wählen. Wie aber entscheiden wir, wo die Mitte liegt? Aristoteles gewinnt dieses Wissen aus der allgemeinen Einschätzung, allerdings nicht der Einschätzung der Vielen, sondern der Wenigen. Nur diejenigen, die die Tugenden bereits als die ersten Prinzipien ihres Handelns und ihrer Gewohnheiten akzeptiert haben - diejenigen, die Aristoteles, die 'Schönen und die Guten nennt (NE 1099a6, 1124a4, 1179b10) - haben die phronesis (Urteilskraft), die Mitte zu bestimmen. Nur sie haben die richtige Art >Auger (NE 1109b20-23, 1126b2-4, 1142a23-30). Das heißt nun aber nicht, dass sie Argumente oder Kriterien dafür vorschlügen, was die Mitte (und was mithin eine Tugend) ist; vielmehr ist Exzellenz der Urteilskraft ihrerseits eine Tugend, die allein ihnen erlaubt, das Gute zu erfassen. Kurz gesagt: Das Gute kann nur durch die Guten bestimmt werden. Wie aber bestimmen wir, wer die Guten sind? Nun, indem wir die Guten fragen. Hier wird das Argument zirkulär.« (Illies 2003, S. 27, Übers. MW)

Nun lässt sich (wie Illies selbst andeutet; ebd., Anm. 20) einwenden, dass Aristoteles ethische Urteilskompetenz in Wahrheit als etwas begriffen hat, das Personen in höherem oder geringerem Maße besitzen können, und nicht als etwas, worüber sie entweder ganz oder gar nicht verfügen. Wenn wir indes von der plausiblen Annahme ausgehen, dass die Unterschiede im Maß des ethischen Urteilsvermögens eher gradueller Art sind, so erscheint es durchaus möglich, dass eine ethisch noch unreife Person die überragende ethische Urteilskompetenz einer anderen Person erkennt und sich an ihr orientiert, ganz ähnlich, wie eine nur mäßig musikalische oder musikalisch noch wenig entwickelte Person die musikalische Bildung einer anderen Person anerkennen und sich von ihr unterrichten lassen kann. Auch finden sich in der Nikomachischen Ethik zumindest Hilfestellungen für die Identifikation ethisch urteilsfähiger Personen: Wie wir gesehen haben, scheiden etwa Personen zu geringen Lebensalters aufgrund ihrer unzureichenden praktischen Erfahrung aus. Zudem kann sich Aristoteles in seiner Berufung auf ethische Vorbilder auch auf die Standards einer aristokratisch geprägten Kultur stützen, in der die elitäre Distinktion zwischen den >Wenigen würdig empfunden wurde. Freilich muss gerade diese Selbstverständlichkeit Anlass zum Misstrauen bieten. Es bleiben Zweifel, ob Aristoteles' Ethik des rechten Maßes nicht doch kriterial unterbestimmt ist. Soweit ethische Vorbilder sich ihrerseits an nichts anderem denn an den Urteilen anderer Vorbilder orientieren können, wird ethisches Urteilsvermögen auf Traditionalismus bzw. eine konventionelle Moralorientierung verkürzt. Ethisch vorbildlich erscheint dann schlichtweg, was als hervorragend anerkannte Bürger seit jeher vorgelebt haben.

Verantwortlichkeit: Ein großer Teil der Nikomachischen Ethik ist spezifischen Überlegungen zu einzelnen Tugenden als Elementen eines guten Lebens gewidmet. Es finden sich jedoch weitere bedeutsame Grundlagenbetrachtungen. Zu nennen ist vor allem die Verantwortungstheorie, die im dritten Buch der Nikomachischen Ethik entwickelt wird. Sie sieht erstmals differenzierte Kriterien der Schuldzuschreibung vor, hat die strafrechtliche Zurechnungslehre nachhaltig geprägt und beschäftigt die philosophische Handlungs- und Verantwortungstheorie bis in die Gegenwart. 


\section{Verantwortung / Verantwortlichkeit}

Der Begriff >Verantwortung` entstammt der rechtlichen Sphäre und bezieht sich auf die Praxis des Einander-Rede-und-Antwort-Stehens. Er ist notorisch vieldeutig und bezeichnet unterschiedliche Arten normativer Relationen zwischen (mindestens) drei Relaten: $S$ (ein Verantwortungssubjekt) ist vor $I$ (einer Verantwortungsinstanz) verantwortlich für $O$ (ein Verantwortungsobjekt, z. B. einen schützenswerten Gegenstand oder eine Handlungsfolge). In einem retrospektiven Sinn wird Verantwortung für Ergebnisse oder Nebenfolgen von aktiven Handlungen oder von Unterlassungen zugeschrieben und bezeichnet dann eine Rechenschaftspflicht oder Schuld. In einem prospektiven Sinn bedeutet die Zuschreibung von Verantwortung die Zuerkennung einer Art Gewährleistungs- oder Fürsorgepflicht für Zustände oder schützenswerte Entitäten. Wer Verantwortung für $O$ trägt, kann auch für $O$ >verantwortlich ' genannt werden; umgangssprachlich vertritt letzter Begriff manchmal auch das wertende Adjektiv >verantwortungsvollı, das eine vorbildliche Wahrnehmung bestehender Verantwortlichkeiten bezeichnet.

Bedingungen der Zurechenbarkeit

Zur Vertiefung
Vieles spricht dafür, dass die Zurechnung von Verantwortung zunächst nicht an die Unterstellung der Freiwilligkeit des zugerechneten Verhaltens gebunden war (Holl 1980). Die Helden der homerischen Epen und vielfach noch der späteren griechischen Tragödien ziehen sich auch dort die Rache der Götter zu, wo sie aus Unkenntnis oder in Abwesenheit von Alternativen gegen deren Gebote verstoßen. Der Philosoph Anaximandros setzt in dem eingangs zitierten Fragment Wirkursächlichkeit und Schuld in eins, unterscheidet also nicht zwischen kausal determinierten und ethisch zurechenbaren Handlungen. Aristoteles hingegen erklärt die Freiwilligkeit von Handlungen oder inneren Einstellungen zur Voraussetzung dafür, dass diese gelobt oder getadelt werden können (1109b30 ff.). Diese Vorausetzung ist nur gegeben, wenn die Handlung freiwillig ist und die handelnde Person Tatherrschaft besitzt, d. h. auch hätte anders handeln können (dieses Kriterium ist in der analytischen Philosophie als Principle of Alternative Possibilities [PAP] diskutiert und insbesondere von Harry Frankfurt [1969] bestritten worden, verteidigt wird es u.a. durch Van Inwagen 1983; vgl. zur Übersicht McKenna/Coates 2015).

\section{(In-)Determinismus und (In-)Kompatibilismus}

Eine bis heute strittige Frage der Ethik liegt an der Schnittstelle zwischen theoretischer und praktischer Philosophie: Wie sind Naturkausalität, Freiheit und Verantwortung zu vereinen? Strittig sind dabei sowohl die Deutung der Naturprozesse als auch die Implikationen der jeweiligen Deutung für die Ethik. Im Hinblick auf die Deutung der Naturgesetze stehen sich Determinismus und Indeterminismus gegenüber. Der Determinismus nimmt an, dass alle Weltzustände mit Notwendigkeit durch vorangehende Weltzustände festgelegt (determiniert) sind, während der Indeterminismus ein gewisses Maß von Unbestimmtheit im Hinblick auf zukünftige Ereignisse annimmt. Im Hinblick auf die Implikationen für die 
Ethik behauptet der Kompatibilismus, dass der Determinismus ethische Verantwortlichkeit nicht ausschließt, während der Inkompatibilismus den Determinismus mit ethischer Verantwortlichkeit für unvereinbar hält.
Aristoteles differenziert Handlungen im Hinblick auf das Maß der Freiheit von äußerem Zwang und unterscheidet entsprechend zwischen (A) Handlungen, die unter unwiderstehlichem Zwang, etwa unmittelbarer physischer Krafteinwirkung vollzogen werden und niemals zurechenbar sind, (B) Handlungen, die von äußerem Zwang frei sind und insofern die Bedingung der Zurechenbarkeit erfüllen sowie (C) sgemischten` Handlungen, die etwa unter Drohung vollzogen werden. Aristoteles hält letztere für eingeschränkt zurechenbar (1110a5ff.). Insofern bei ihnen eine bewusste Abwägung zwischen zwei Übeln erfolge, glichen sie allerdings eher den freien Handlungen. Die prinzipiell zurechenbaren Handlungen der Klassen B und C - also alle Handlungen, die nicht vollständig durch äußere Einwirkung erklärbar sind - differenziert Aristoteles weiterhin im Hinblick auf ihr inneres Zustandekommen. Hier unterscheidet er zwischen (1) Handlungen, die aktuell unter Tatherrschaft stehen, insofern sie bewusst und mit überlegtem Vorsatz vollzogen werden, und (2) solchen Handlungen, die nur potentiell unter Tatherrschaft stehen, entweder (2.1) weil sie aus dem Affekt geboren sind, oder (2.2) weil seitens des Handelnden ein Irrtum über Normen (2.2.a) oder ein Irrtum über Handlungsumstände (2.2.b) vorliegt, die für die Beurteilung der Handlung relevant sind. Während bewusste Vorsatzhandlungen (1) immer zurechenbar sind, hängt die Zurechenbarkeit der übrigen Handlungen (2) jeweils von zusätzlichen Bedingungen ab. Deren gemeinsamer Nenner lässt sich dahingehend zusammenfassen, dass Handlungen insoweit zurechenbar sind, als die Bedingungen, die ihr Zustandekommen erklärlich machen, wiederum der handelnden Person zugeschrieben werden können. So ist eine Handlung des Typs 2.1, die im Zustand schwerer Trunkenheit und daher fehlender aktueller Tatherrschaft begangen wird, der handelnden Person gleichwohl zurechenbar, wenn sie die Trunkenheit selbst bewusst und vorsätzlich herbeigeführt hat, nicht aber, wenn sie gegen ihren Willen in den Zustand des Vollrauschs versetzt wurde (1113b30 ff.). Ebenso ist eine aufgrund eines Irrtums über Normen vollzogene Handlung des Typs 2.2.a dann zurechenbar, wenn die Kenntnis der übertretenen Norm von der Person erwartet werden konnte, wenn die Unkenntnis der Verbotsnorm also ihrerseits Grund zum Tadel ist. Dies ist vor allem bei grundlegenden, von Natur aus gültigen Normen der Fall.

Gerechtigkeit als Relation: Abschließend sei noch auf die vor allem im fünften Buch der Nikomachischen Ethik entwickelte Gerechtigkeitstheorie hingewiesen. Aristoteles bemüht sich hier zunächst um die Klärung von Missverständnissen, indem er verschiedene Gebrauchsweisen des Gerechtigkeitsbegriffs unterscheidet. Der Begriff werde manchmal als gleichbedeutend mit Gesetzmäßigkeit überhaupt verstanden und sei dann nichts anderes als die Gesamtheit all derjenigen Tugenden, die den Umgang mit anderen Personen beträfen (1129b30 ff.). So verstanden,
Handlungsdifferenzierung nach Aristoteles 
Gerechtigkeit und Gleichheit

Zweierlei Recht ziele Gerechtigkeit nicht primär auf das Gut der handelnden Person, sondern auf das Gut anderer Handlungsbetroffener (1130a1 ff.). In einem spezifischeren Sinn ist Gerechtigkeit eine Tugend, die mit Gleichheit zu tun hat (1130a20 ff.) und insofern wiederum mit einer Mitte zwischen zwei Extremen, da das Gleiche zwischen dem Zuviel und dem Zuwenig liegt (1131a5ff.). Bei der Tauschgerechtigkeit, die Transaktionen zwischen Personen betrifft, gilt die arithmetische Gleichheit: Der Austausch ist dann gerecht, wenn der Wert von Leistung und Gegenleistung gleich ist. Im Fall der Verteilungsgerechtigkeit bezieht sich Gleichheit dagegen nicht unmittelbar auf die jeweils zugeteilten Güter, dergestalt, dass jeder Anspruchsberechtigte notwendigerweise gleich viel erhalten müsste. Vielmehr bezieht sie sich auf die Proportion zwischen der jeweiligen Anspruchsgrundlage einerseits und den jeweils bezogenen Gütern andererseits. Eine egalitäre Verteilung, bei der alle Anspruchsberechtigten gleich viel erhalten, ist lediglich ein Sonderfall einer im Sinne der Proportionalität gleichmäßigen Verteilung. Gerecht wäre sie genau dann, wenn die jeweilige Anspruchsgrundlage (z. B. die jeweilige Bedürftigkeit oder das jeweilige Verdienst) aller Anspruchsberechtigten ebenfalls genau gleich wäre. Dabei konstatiert Aristoteles, dass hinsichtlich der Frage, auf welcher Anspruchsgrundlage Leistungen zugemessen werden sollen, kein Konsens besteht.

Positives versus natürliches Recht: Im Kontext der Gerechtigkeitstheorie führt Aristoteles auch die wichtige Unterscheidung zwischen dem durch politische Vereinbarung gesetzten Recht einerseits und dem von Natur aus geltenden Recht andererseits ein (1134b18ff.). Ersteres regelt Sachverhalte, die, zunächst indifferent, erst durch die autoritative Festlegung eine bestimmte normative Bedeutung erhalten. Entsprechend können in unterschiedlichen Gemeinschaften unterschiedliche rechtliche Regelungen gelten. Das natürliche Recht ist demgegenüber überall dasselbe und von den Meinungen der Menschen unabhängig. Da Aristoteles im Rahmen seiner Naturphilosophie strikt zwischen dem schlechthin unwandelbaren Teil der Natur (wozu er den Sternenhimmel zählt) und dem prinzipiell veränderlichen Teil der Natur unterscheidet, fügt er allerdings an, dass auch das Naturrecht nicht schlechthin unveränderlich sei, da die menschliche Natur selbst, anders als die der Götter, als wandelbar gelten müsse. Bei den Sophisten diente die Gegenüberstellung der durch

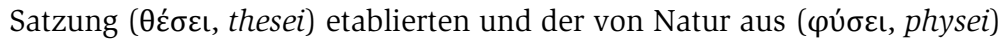
geltenden Gesetze meist der polemischen Funktion, die Verbindlichkeit der positiven Gesetze zu unterminieren. Aristoteles geht es hingegen ebenso wie späteren Naturrechtstheoretikern oder analog auch wie David Hume bei seiner Unterscheidung zwischen natürlichen und künstlichen Tugenden - eher um die Abgrenzung von Geltungsbereichen. Das Naturrecht legt normative Mindestansprüche fest und begrenzt so den Spielraum legitimer Vereinbarungen. Innerhalb der durchs Naturrecht gezogenen Grenzen können durch Vereinbarungen jedoch durchaus verbindliche Festlegungen getroffen werden. 


\section{3 | Systematische Fragen}

Neben Aristoteles' Tugendethik sind in der Philosophie der griechischen Alternative und römischen Antike zahlreiche andere Modelle einer Ethik des guten Strömungen Lebens entwickelt worden. Zu erwähnen ist insbesondere die Philosophie der Stoa und der (Neu-)Platonismus, die maßgeblichen Einfluss auch auf die christliche Philosophie des Mittelalters (und später, in einem frischen Zugriff auf die Quellen, auf das Denken der Renaissance) ausgeübt haben, bevor und auch noch nachdem Aristoteles durch Albertus Magnus (ca. 1193-1250) und dessen Schüler Thomas von Aquin (ca. 1224-1274) zur zentralen philosophischen Bezugsfigur der orthodoxen Kirchenlehre erhoben wurde. Als populäre, aber viel bekämpfte und nicht selten verleumdete Nebenströmung soll die materialistische und hedonistische Ethik Epikurs (ca. 341-271 v. u. Z.) zumindest erwähnt werden. Sie baut auf die atomistische Naturphilosophie Leukipps (geb. ca. 470 v. u. Z.) und Demokrits (ca. 460-370 v.u. Z.) und zielt auf ein ruhiges, an vermeidbarem Leiden und insbesondere an irrationalen Ängsten armes Leben. Epikur vertritt damit einen snegativen<, primär auf die Vermeidung von Leiden zielenden Hedonismus; eine Position, die mit dem polemischen Zerrbild des ausschweifenden Genüssen nachstrebenden Epikureers nicht viel gemein hat.

Hedonismus (von griech. ந்ঠovń, hedone: Lust) wird eine axiologische (werttheoretische) Auffassung genannt, der zufolge die von Lebewesen empfundene Lust - subjektiv erlebtes Wohlbefinden - das einzige oder jedenfalls das zentrale Gut darstellt, das intrinsisch, d. h. um seiner selbst willen, wertvoll ist. Hedonistische Ansätze stehen in Spannung zu 'perfektionistischen، Deutungen des guten Lebens.

Perfektionismus nennt man solche Konzeptionen, die das Ziel eines guten Lebens in der möglichst vollkommenen Realisierung von Wesensmöglichkeiten bzw. in der Selbstentfaltung erblicken (Hurka 1993; Wall 2017; Henning 2015).

Entsprechend der primär systematischen Zielsetzung des vorliegenden Buchs, die klassische Positionen nur exemplarisch in den Blick nimmt, werden alternative Ansätze antiker Tugendethik nicht detailliert vorgestellt. Vielmehr werden die von Aristoteles aufgeworfenen Fragen und vertretenen Positionen noch einmal aus einer systematischen Perspektive diskutiert. Vorgriffe auf den Inhalt späterer Kapitel sind dabei nicht zu vermeiden. Eventuell empfiehlt es sich, die folgenden Absätze nach der Lektüre der anschließenden Kapitel noch einmal zu lesen. 
Verhältnis

zwischen Glück und Gerechtigkeit

\subsection{1 | Glück und Moral}

Verschiedene

Glück und Gerechtigkeit: Aristoteles' Ethik geht von der Frage nach der

Ethiktypen Form eines guten Lebens aus: Was bedeutet es überhaupt, jemanden glücklich zu nennen? Was macht ein glückliches Leben aus? Welche allgemeinen praktischen Orientierungen und welche äußeren Glücksumstände tragen dazu bei? Welche Kompetenzen müssen wir einüben, um unserem Leben die Form eines guten Lebens zu geben? Aristoteles’ Tugendethik steht damit exemplarisch für einen Ethiktyp, der als Glücksethik, als Ethik des guten Lebens oder als Eudaimonismus bezeichnet wird. Da solche Ethiken typischerweise fragen, wonach wir streben sollen, um gut zu leben, fallen sie zugleich in die Kategorie der Strebensethik. Die Frage nach dem guten und glücklichen Leben steht jedoch nicht in allen Ethiken im Mittelpunkt. Einen alternativen Ethiktypus verkörpert die Gerechtigkeitsethik. Gerechtigkeitsethiken versuchen zu klären, was wir überhaupt tun und unterlassen dürfen, was wir wechselseitig einander schulden, wer welche Rechte und Pflichten hat. Soweit Gerechtigkeitsethiken üblicherweise Pflichten und Sollensvorschriften zu begründen versuchen, fallen sie zugleich in die Kategorie der Sollensethik. Typischerweise sind Ethiken des guten Lebens also zugleich Strebensethiken, Gerechtigkeitsethiken zugleich Sollensethiken.

Andauernde Kontroversen: Freilich bringen diese modernen Unterscheidungen einige Herausforderungen mit sich. So ist zu klären, inwieweit gutes Leben und Gerechtigkeit begrifflich oder zumindest empirisch zusammenhängen. Geht man etwa von der plausiblen Annahme aus, dass Gerechtigkeitsansprüche zumindest auch Ansprüche auf notwendige Bedingungen eines guten und glücklichen Lebens umfassen, dann können auch Gerechtigkeitsethiken nicht ohne glücksethische Überlegungen auskommen, da ohne solche Überlegungen der Gegenstand von Gerechtigkeitsansprüchen nicht geklärt werden kann. Umgekehrt gibt es gute Gründe für die Annahme, dass auch eine Ethik des guten Lebens nicht ohne gerechtigkeitsethische Annahmen auskommen kann. So scheint es plausibel, dass ein gelingendes Leben auf Formen sozialer Anerkennung angewiesen ist, die sich nur innerhalb gerechter Interaktionsbedingungen entfalten können (Rössler 2017, S. 54 f., 304 ff., 322 ff.; vgl. Honneth 1992a; Seel 1995, S. 194 ff.). Wie eng und von welcher Art die Abhängigkeiten zwischen glücks- und gerechtigkeitsethischen Annahmen genau sind, wird auch gegenwärtig noch kontrovers diskutiert. So schlagen Vertreter/innen des politischen Liberalismus und Libertarismus Grundprinzipien gerechten Zusammenlebens vor, die mit unterschiedlichen Vorstellungen des guten Lebens vereinbar sein sollen. Ziel der politischen Gerechtigkeitsethik ist demnach, Prinzipien zu begründen, deren Institutionalisierung allen gleichermaßen ermöglichen soll, ihre individuell unterschiedlichen Vorstellungen vom guten Leben zu realisieren. Die Gerechtigkeitsethik könne und solle sich daher mit wenigen, `schwachen`, rein formalen, allgemein gehaltenen und relativ unstrittigen Annahmen darüber begnügen, was ein gutes und glückliches Leben ausmacht (vgl. klassisch Rawls 1975, Kap. 7; Rawls 1992, Kap. 7; Rawls 1998, Kap. 5; siehe Kap. 7). Neo-Aristoteliker/innen, Neo-Hegelia- 
ner/innen, Kommunitarist/innen und manche phänomenologisch orientierten Philosoph/innen halten die begrifflichen oder empirischen $\mathrm{Zu}$ sammenhänge zwischen Glücks- und Gerechtigkeitsvorstellungen hingegen für deutlich enger. Häufig interpretieren sie gerade die liberale Trennung zwischen Gerechtigkeits- und Glücksfragen als Ausdruck eines bestimmten, spezifisch modernen und wesentlich individualistischen Konzepts vom guten Leben (u. a. Taylor 1986; zur Übersicht vgl. Honneth 1992b, Reese-Schäfer 1997). Gerechtigkeitskonzepte seien in Wahrheit niemals sneutrak gegenüber Vorstellungen vom glücklichen Leben. Neben Abhängigkeiten zwischen Glück und Gerechtigkeit sind auch Spannungen und Konflikte möglich. Das Bestreben, das eigene Glück oder das Glück Anderer zu fördern, kann mit Gerechtigkeitsforderungen kollidieren. Die Frage, wie solche Kollisionen zu interpretieren und aufzulösen sind - ob und welche theoretischen oder praktischen Vorrangverhältnisse zwischen Glück und Gerechtigkeit bestehen - gehört zu den kontrovers diskutierten Fragen der Ethik. Lassen sich, wie der klassische Glücksutilitarismus annimmt, Gerechtigkeitsforderungen letztlich immer in Forderungen einer verallgemeinerten Glücksmaximierung übersetzen, weil jeweils genau diejenige Handlung gerecht ist, die >das größte Glück der größten Zahk erwarten lässt? Oder ist vielmehr Gerechtigkeit die übergreifende und vorrangige Beurteilungsperspektive, weil Gerechtigkeit den Rahmen setzt, innerhalb dessen individuelle oder gemeinschaftliche Pläne vom guten Leben überhaupt verfolgt werden dürfen?

Glücksbegriff antiker Tugendethik: Wenn man Aristoteles' Ethik als Glücks- und Strebensethik bezeichnet, ordnet man sie in ein Schema ein, das sich in der skizzierten Form erst später etabliert hat. Die moderne Vorstellung, dass moralische und rechtliche Normen dem individuellen Glücksstreben Grenzen setzen müssen, ist für antike Tugendethiken ebenso wenig kennzeichnend wie die Annahme, dass Glück in erster Linie einen subjektiven Gemütszustand beschreibt. Glück und sittliche Kategorien wie Gerechtigkeit oder Schicklichkeit werden in den antiken Tugendethiken regelmäßig als untrennbar verbunden gedacht. Für die später etwa von Kant betonte Unterscheidung zwischen Fragen des je eigenen Lebensglücks (Kant nennt sie spragmatisch`) und moralischen Fragen der Gerechtigkeit; für die Unterscheidung zwischen demjenigen, wonach zu streben klug und ratsam ist, und demjenigen, was unbedingt geboten ist, finden sich bei Aristoteles lediglich Ansätze. So räumt er in einer Diskussion von Verantwortlichkeit im Fall der Erpressung ein, "zu einigen Dingen« - gemeint sind sschändlicher Dinge wie Muttermord - solle »man sich vielleicht überhaupt nicht zwingen lassen, sondern eher sterben und das Schlimmste erdulden " (NE 1110a). Allerdings sei es »[z]uweilen schwierig, zu entscheiden, für was man sich entscheiden und welches von zwei Dingen man aushalten soll« (ebd.), und zwar insbesondere dann, wenn man zwischen `Schmerzlichem` und `Schändlichem` entscheiden müsse. Diese Überlegung deutet an, dass das individuelle Glücksstreben mit demjenigen kollidieren kann, was gerecht und schicklich ist. Mehr noch: Man könnte in Aristoteles' Begründung für die Entscheidungsschwierigkeiten einen Hinweis darauf sehen, dass Schmerz (als Übel im Hinblick auf das eigene Lebensglück) und Schändliches (als moralisches Übel) qualitativ
Vorrang des Gerechten/Vorrang des Guten?

Aristoteles' Kompromissversuch 
Moralistischer Glücksbegriff der Stoa unterschiedlichen Kategorien zugehören, und dass eben dies der Grund ist, warum sie nicht ohne Weiteres gegeneinander aufzurechnen sind. Allerdings bleibt es eben bei Andeutungen. Die zu treffende Entscheidung zwischen Schändlichem und Schmerzlichem soll, wie alle ethischen Entscheidungen, letztlich doch an dem einen Ziel des guten Lebens orientiert sein, in dem eudaimonistische und moralische Gutheit gerade nicht streng geschieden sind. Aristoteles' eudaimonia schließt Elemente >moralischer Exzellenz vielmehr ausdrücklich ein. Diese Integration moralischer Elemente in den Glücksbegriff ist für die antiken Tugendethiken generell kennzeichnend (zu Charakter und Entwicklung des antiken Glücksbegriffs vgl. genauer Horn 1998, S. 61 ff.).

Stoischer Glücksbegriff: Schon die Kontroversen zwischen antiken Philosophenschulen wecken allerdings Zweifel, ob diese Integration zwanglos gelingen kann. Vertreter der Stoa etwa gehen in der >Moralisierung des Glückskonzepts noch viel weiter als Aristoteles. Einerseits schreiben sie dem Maßstab der Sittlichkeit strikten Vorrang vor allen nicht-sittlichen Überlegungen oder Neigungen zu. Ebenso wie später Kant und viele andere Moralphilosophen vertreten sie die These der strikten Vorrangigkeit (overridingness) der Moral. Die sittliche Tugend urteilt laut dem stoischen Philosophen Seneca dem Jüngeren »über alle Dinge, über sie nichts« (Seneca 1999, Bd. IV, S. 33. [Ep. mor. ad Lucilium 71, 20]). Andererseits - und anders als Kant - suchen Seneca und andere Stoiker die Vorrangigkeitsthese aber mit der auch von Aristoteles vertretenen Vorstellung zu vereinbaren, dass wir uns an nichts anderem denn an dem einen Ziel des gelungenen und glücklichen Lebens orientieren sollen dem höchsten Gut. Es bleibt ihnen daher nur die Möglichkeit, das glückliche Leben vollständig mit dem sittlich vorbildlichen Leben gleichzusetzen (ganz in der Tradition des Platonischen Sokrates, dessen Auffassung, es sei ‘besser`, Unrecht zu leiden als Unrecht zu tun, bereits erwähnt wurde). Während Aristoteles zufolge auch der vollkommen Tugendhafte zum vollkommenen Glück noch auf günstige Lebensumstände angewiesen bleibt, soll der stoische Weise davon ganz unabhängig sein. Im Bewusstsein der Tatsache, dass diese Auffassung "wunderlich« erscheinen muss, bekräftigt Seneca gleichwohl: »Bei Tische zu liegen ist ein Übel, auf der Folterbank zu liegen ist ein Gut, wenn jenes schimpflich, dieses vollkommen geschieht" (ebd., S. 33 ff. [71, 21]). Denn sittliche Vollkommenheit ist das einzige Gut (ebd., S. 41 [71, 32]). Nur unsere eigene Schwachheit kann uns dies verkennen lassen (ebd., S. 35 [72, 22 ff.]). Die stoische Auffassung, wonach die sittliche Tugend nicht nur das höchste, sondern das einzige Gut darstellt, ist allerdings nicht nur »wunderlich«, sondern sorgt auch für eine Reihe von Folgeproblemen.

»To say that >Virtue is the highest good, « is a proposition to which every one who aspires to the spiritual life must yield assent with his lips, even if he has not yet learnt to believe it in his heart. But alter it into >Virtue is the only good, ‘ and by that slight change it becomes at once the teeming mother of paradoxes. « (Stock 1908 , S. 60 f.)

Eines der Probleme ist folgendes: Soziale Tugenden wie Gerechtigkeit, Hilfsbereitschaft oder Großzügigkeit beziehen sich regelmäßig auf For- 
men sozialer Anerkennung und Achtung oder die Zuteilung von sozialen Leistungen oder materiellen Gütern. Sollte all diesen vermeintlichen Gütern indes keinerlei Wert zu kommen, weil sittliche Tugend selbst das einzige Gut darstellt und weil die Selbstachtung des Weisen allein davon abhängt, ob er den Standards der natürlichen Vernunft gehorcht, verlören all diese sozialen Tugenden gleichsam ihren Gegenstand. Man könnte anderen dann lediglich dadurch etwas Gutes tun, dass man ihnen Gelegenheit gibt, sich tugendhaft zu betragen, was die absurde Konsequenz hätte, dass man ihnen etwas Gutes täte, wenn man ihre Tugend auf die Probe stellte. Umgekehrt täte man ihnen nicht wirklich etwas Schlechtes, wenn man sie beraubte, verletzte oder missachtete. Auch unabhängig von solchen Paradoxien belasten sich stoische Philosophen mit einer schweren Aufgabe. Denn sie wollen ihr Publikum nicht nur von einer veränderten Redeweise überzeugen, indem sie für eine Deutung des Wortes "Glück" plädieren, die der gängigen Verwendung widerspricht. Sie wollen es auch dazu bewegen, ein anderes Ziel anzustreben als bisher. Dazu müssen sie ihm vor Augen führen, dass es sich in seinen Vorstellungen vom eigenen Lebensziel grundsätzlich getäuscht hat. Das ist eine schwere Hypothek, zumal für eine Philosophenschule, die in anderen Zusammenhängen den consensus gentium, die Übereinkunft der Völker, als Argument anführt.

Aristoteles' Glückskompromiss: Verglichen mit der Tugendlehre der Stoa ist Aristoteles' Ethik weniger radikal. Sein Glücksbegriff soll erfassen, wonach alle Wesen natürlicherweise zu streben geneigt sind. Aristoteles will dabei explizit an gängige Auffassungen anknüpfen. Entsprechend vertritt er die Überzeugung, dass »der Glückseligkeit Lust beigemischt sein muss « (NE, 1177a). Freilich meint er damit eine besondere Art von Lust, nämlich eine, die die vollkommene Tätigkeit begleitet (vgl. Ricken 1995). Mit dieser Vorstellung einer der vollkommenen Tätigkeit eigenen Lust sucht er, zwei unterschiedliche Glücksbegriffe miteinander $\mathrm{zu}$ versöhnen:

- zum einen die Vorstellung eines natürlicherweise angestrebten Zustands langfristigen subjektiven Wohlbefindens, der auch von äußeren Umständen abhängig ist;

- zum anderen die Vorstellung einer maximal selbstgenügsamen, tugendhaften Tätigkeit; einer vollkommenen Aktualisierung der spezifischen Wesensmöglichkeiten, die Bewunderung und Anerkennung verdient.

Ist eine Versöhnung dieser beiden Vorstellungen jedoch überhaupt denkbar, oder läuft der Versuch auf einen unklaren Kompromiss hinaus? Julia Annas zufolge führt Aristoteles' Vorschlag, Glück gewissermaßen als aus Tugend und äußeren Gütern zusammengesetzt zu bestimmen, zu einer schwankenden und instabilen Position (Annas 1993, S. 368). Ernst Tugendhat ist der Auffassung,

»dass [...] die ganze Tugendlehre des Aristoteles zwischen den zwei Möglichkeiten schillert, ob es sich um Glückstugenden oder um moralische Tugenden handelt.« (Tugendhat 1993, S. 248)

Mehrdeutigkeit des aristotelischen Glücksbegriffs 
Moderne Interpretationen der aristotelischen Tugendethik
Gerade weil Aristoteles' habe zeigen wollen, dass sittliche Tugend für ein glückliches Leben essentiell sei, wäre es nach Tugendhats Einschätzung "angemessener " gewesen, "wenn die beiden Begriffe erst einmal deutlich getrennt worden wären« (ebd., S. 249).

Deutungsmöglichkeiten: Für die Mehrdeutigkeit der aristotelischen Ethik spricht jedenfalls die Vielfalt der Interpretationen, Beurteilungen und Aktualisierungsversuche. Die Reaktionen auf Aristoteles' Tugendethik lassen sich grob danach unterscheiden, ob sie sie lediglich als Beitrag zur Glückslehre oder auch als Beitrag zur Sittenlehre interpretieren sowie danach, für wie überzeugend und aktuell relevant sie den jeweiligen Beitrag erklären. Insbesondere drei Positionen sind verbreitet:

1. Eine erste Deutung verteidigt den Standpunkt der modernen Moralphilosophie gegenüber der aristotelischen Tugendethik und wird etwa von Kant vertreten. Sie interpretiert Aristoteles' Ethik wesentlich als Lebenslehre, die auf ein glückliches Leben - primär verstanden im Sinne eines langfristigen persönlichen Wohlbefindens - zielt. Zugleich geht sie davon aus, dass das Versprechen der Tugendethik, Ratschläge für ein glückliches Leben zu geben, von einer seriösen - sich als Wissenschaft verstehenden - Philosophie nicht einzulösen ist, und zwar vor allem deshalb, weil die Vielfalt konkreter Lebensumstände und -entscheidungen keine strikt allgemeingültigen Aussagen über das Glück zulässt. Soweit Aristoteles im Rahmen dieser Deutung auch eine Sittenlehre zugeschrieben wird, wird diese als abhängig von der Glückslehre betrachtet. Daraus folgt wiederum, dass auch die Sittenlehre unhaltbar ist, weil sie auf einem nicht tragfähigen Fundament errichtet ist. Der unbedingte (`kategorische`) Forderungscharakter moralischer Pflichten könne nicht aus bloßen Klugheitsratschlägen für das eigene Lebensglück abgeleitet werden. Kurz: Aristoteles' Ethik scheitert sowohl als Glücks- als auch als Sittenlehre. Ersteres, weil eine wissenschaftliche Glückslehre unmöglich ist, Letzteres, weil die Sittenlehre auf fundamental falschen Prinzipien basiert.

2. Eine zweite Deutung betont ebenfalls die glücksethischen Elemente der aristotelischen Ethik. Sie teilt jedoch nicht die für die erste Deutung wesentliche Annahme, Moralphilosophie dürfe nur solche Prinzipien zum Gegenstand haben, deren Allgemeinheit und Notwendigkeit der von Naturgesetzen gleichkomme. Entsprechend hält sie das philosophische Nachdenken über die Form eines guten Lebens für weiterhin fruchtbar. Im Sinne einer Ergänzung der auf sollensethische Fragen konzentrierten modernen Moralphilosophie will sie an die aristotelische Tradition anknüpfen (z. B. Seel 1995).

3. Eine dritte Position ist gegenüber der modernen Moralphilosophie noch kritischer. Auch sie möchte an die aristotelische Tugendethik anknüpfen, jedoch nicht nur zum Zweck einer Ergänzung, sondern mit dem Ziel einer mehr oder weniger radikal ansetzenden Revision der gegenwärtigen Moralphilosophie (z. B. MacIntyre 2007, Slote 2001).

Jede dieser Positionen bietet noch einmal Raum für unterschiedliche Ansätze; auch ist die Aufzählung nicht erschöpfend. So betonen einige Arbeiten seit den 1980er Jahren auch wieder Übereinstimmungen zwischen 
antiken Tugendethiken und etwa der Moralphilosophie Kants (vgl. etwa Herman 1993). Im Folgenden können nur einige zentrale Überlegungen zur Sprache kommen.

\subsection{2 | Ethik des guten Lebens}

Subjektivität des Gegenstands: Inwieweit das gute Leben überhaupt ein Gegenstand der Philosophie sein kann, ist keineswegs ausgemacht. Zweifel speisen sich meist aus den Überlegungen,

1. dass Philosophie danach strebe, durch rationale Argumentation allgemeine, objektiv gültige Aussagen oder Prinzipien zu begründen,

2. dass die relevanten Vorstellungen - und vor allem: die konkreten Erfahrungen - eines glücklichen oder sinnvollen Lebens extrem vielgestaltig und subjektiv seien,

3. dass diese Vorstellungen und Erfahrungen deshalb nicht Gegenstand philosophischer Erkenntnis sein könnten.

Dabei setzt die zweite Prämisse bereits die Einschätzung voraus, dass es nicht möglich ist, ein allgemeingültiges Bild eines gelingenden Lebens beispielsweise aus der objektiven Wesensnatur des Menschen abzuleiten, wie dies Aristoteles mittels des Ergon-Arguments versucht hat. Diese Einschätzung stützt sich auf Gründe, die im folgenden Kapitel noch näher zur Sprache kommen: erstens die Zurückweisung des klassischen, auf eine teleologische Naturphilosophie gestützten, ethischen Naturalismus und zweitens einen normativen Individualismus, der sich im Ausgang des Mittelalters gegen die klassische Wesensmetaphysik durchzusetzen beginnt. Wenn man nun das Scheitern des Ergon-Arguments einräumt und überhaupt die Prämissen der Überlegung akzeptiert - ist die Schlussfolgerung dann zwingend?

Musik als Beispiel: Die Antwort hängt vor allem davon ab, was mit den beiden Prämissen genau zugestanden ist. Schließt die behauptete Subjektivität und Vielgestaltigkeit des Gegenstands jede wissenschaftliche Beschäftigung mit diesem Gegenstand aus? Auch Musik ist ja beispielsweise ein äußerst vielgestaltiger Gegenstand, dessen Wahrnehmung in gewissem Sinne ebenfalls subjektiv ist. Das schließt jedoch nicht aus, dass sich Musiktheorie, Musikerziehung, Instrumental- und Kompositionsunterricht sowie Musikkritik in rationaler Weise mit diesem Gegenstand beschäftigen und dass es ihnen gelingt, sowohl verallgemeinerbares Wissen als auch verschiedenartige Erfahrungen und Fertigkeiten zu vermitteln, die zu einem genaueren und lebendigeren Verständnis ihres Gegenstandes beitragen. Dieser Vergleich kann eine gründliche Erörterung natürlich nicht ersetzen; er mag aber deutlich machen, dass das Argument gegen die Möglichkeit einer philosophischen Glücksethik nicht ohne Weiteres zwingend ist. Zugleich mag er aber auch Grenzen dessen illustrieren, was von der Glücksethik sinnvollerweise zu erwarten ist: Ebenso wie die Befolgung allgemeiner Kompositions- oder Improvisationsregeln allein nicht hinreichen mag, eine musikalisch überzeugende Komposition oder Improvisation hervorzubringen, wird allein die Befol-

Wissenschaft und Kunst 
Aristoteles' Fragestellung unabhängig von der Antwort gung genereller glücksethischer Regeln kaum hinreichen, um ein glückliches und sinnvolles Leben zu führen. Zwischen Theorie und Praxis, zwischen Wissenschaft und Kunst, bleibt ein Abstand bestehen. Das spricht jedoch nicht gegen die Möglichkeit und Fruchtbarkeit eines allgemeinen, durch Erfahrung und Urteilskraft zu ergänzenden >Umrisswissens`, wie es Aristoteles auf dem Gebiet der Ethik angestrebt hat.

Unvermeidlichkeit der glücksethischen Frage: Es lässt sich sogar fragen, inwieweit sich die Beschäftigung mit der glücksethischen Frage, wie sie von Aristoteles eingeführt worden ist, überhaupt sinnvoll vermeiden lässt, sobald man einmal angefangen hat, über den relativen Wert verschiedener Handlungsoptionen nachzudenken. Denn bei der Einführung der Fragestellung vermeidet Aristoteles voreilige inhaltliche Festlegungen. Er geht nicht schon von einer bestimmten Glücksvorstellung aus; geschweige denn von bestimmten philosophischen Annahmen, wie sie etwa dem Ergon-Argument zugrunde liegen. Vielmehr führt er zunächst lediglich das Konzept eines übergreifenden Ziels unserer Lebenspraxis ein. Darin sieht er ein Erfordernis einer konsistenten Handlungsstruktur: Weil unsere verschiedenen praktischen Verrichtungen jeweils auf ein bestimmtes Gut zielen, das ihnen Ordnung und Sinn verleiht, muss es auch ein übergreifendes Ziel der menschlichen Lebenspraxis insgesamt geben, wenn denn auch diese Lebenspraxis als solche eine vernünftige Struktur und einen Sinn haben soll. Denn ohne ein solches übergreifendes Ziel würde unserem Leben eine konsistente Ausrichtung fehlen. Wir hätten keinen Maßstab, anhand dessen wir den relativen Wert der unterschiedlichen Ziele möglicher alternativer Betätigungen gegeneinander abwägen könnten. Dies wiederum ließe auch den jeweiligen Wert der spezifischeren Ziele unklar erscheinen, da wir uns ja letztlich nicht rational, sondern nur willkürlich (`dezisionistisch $`$ ) für eines dieser Ziele und gegen ein anderes entscheiden könnten. Erst im Anschluss an diese Überlegung stellt Aristoteles fest, dass das gesuchte Endziel üblicherweise als eudaimonia bezeichnet wird. Eudaimonia wird dabei zunächst nur als inhaltlich noch unbestimmte Variable für dasjenige eingeführt, woran wir unser Leben insgesamt orientieren sollten. Erst im Anschluss sucht Aristoteles in der Auseinandersetzung mit gängigen Vorstellungen zu klären, worum es sich dabei handeln könnte, und erst in diesem Rahmen entwickelt er schließlich die oben skizzierten Überlegungen und Argumente für seine spezifischen inhaltlichen Auffassungen vom guten Leben. Man kann Aristoteles spezifische Antworten auf die glücksethische Frage daher zurückweisen, die Frage selbst aber für sinnvoll oder gar (im angedeuteten Sinne) unvermeidlich halten.

Dominantes versus inklusives Lebensziel: Allerdings weist Aristoteles' Frage nach >dem` Ziel der menschlichen Lebenspraxis eine Unklarheit auf, auf die insbesondere Hardie (1965) aufmerksam gemacht hat: Aristoteles' Überlegungen zur Notwendigkeit eines übergreifenden Lebensziels zeigen nämlich nicht, dass das gesuchte übergreifende Ziel ein dominantes Ziel zusätzlich zu und sozusagen süber` den verschiedenen Teilzielen sein müsste, dergestalt, dass alle übrigen Handlungsziele wiederum nur Mittel zur Realisierung des übergreifenden Ziels darstellen würden. Das übergreifende Ziel könnte sich als inklusives Ziel auch aus 
verschiedenen Teilzielen zusammensetzen, sofern sie in nachvollziehbarer Weise gegeneinander abgewogen und in einen vernünftigen Lebensplan eingebettet sind. Für die Interpretation der Aristotelischen Ethik sind die beiden Alternativen vor allem im Hinblick auf das Verhältnis zwischen der theoretischen und der politischen Lebensform relevant. Die Tätigkeit der theoretischen Betrachtung scheint sowohl dem Ergon-Argument als auch dem Autarkiekriterium besonders zu entsprechen. Man könnte daher annehmen, dass es sich bei dieser Tätigkeit um das dominante Ziel des menschlichen Lebens handelt, dem die übrigen Tätigkeiten untergeordnet sind. Mindestens ebenso plausibel ist die Annahme, dass Aristoteles im Sinne eines inklusiven Lebensziels für eine harmonische Einbettung theoretischer und politischer Betätigungen in eine vernünftige Lebensform plädieren wollte (vgl. Wolf 2013, S.249f.). Wichtiger als diese Interpretationskontroversen ist im vorliegenden Zusammenhang, dass die Glücksethik nicht auf eine der beiden Interpretationen eines übergreifenden Lebensziels festgelegt ist. Um den Eindruck zu vermeiden, dass eine Ethik des guten Lebens auf die Annahme eines dominanten Lebensziels festgelegt ist, wäre das Ziel ihrer Suche vielleicht allgemein als vernünftige Lebensorientierung $\mathrm{zu}$ beschreiben.

Glück als emotionaler Zustand: Die vernünftige Lebensorientierung zielt auf ein gutes, geglücktes Leben. Dieser Begriff scheint im heutigen Kontext angemessener als die Rede von `Glückı, weil dieser Begriff gegenwärtig meist in der engeren Bedeutung eines subjektiven Empfindens verwandt wird (Haybron 2008, S. 3 ff.; 2011). Leitbilder eines geglückten Lebens scheinen jedoch unterschiedliche Wertdimensionen zu umfassen. Als gut und wertvoll kann das Leben zunächst im Hinblick auf subjektive Empfindungen von Glück oder Freude erfahren werden. Hier erstreckt sich ein weites Spektrum qualitativ und quantitativ unterschiedlicher und teils auch ambivalenter Empfindungen, angefangen vom bloß negativen Gut der Freiheit von diversen physischen und psychischen Schmerzen bis hin zu vielfältigen Erfahrungen von Zufriedenheit, Wohlsein, Lust und Erfüllung. Solche Empfindungen haben einerseits eine solide Basis in unserer biologischen Konstitution, die auch die weitreichende Übereinstimmung in Bezug auf Werturteile über physische Empfindungen erklärt. So würde kaum jemand bestreiten, dass der Schmerz, den Opfer schwerer Verbrennungen erleiden, ein Übel und prima facie einem guten Leben abträglich ist (vgl. Nagel 1992, S. 270 ff.). Andererseits sind unsere emotionalen Erlebnisse schon als solche bedingt und überformt durch Überzeugungen, Interpretationen, Wertentscheidungen und charakterliche Haltungen. Zum einen können sie das Ergebnis von Situationseinschätzungen sein, die mehr oder weniger berechtigt und durch Argumente beeinflussbar sind - die Eifersucht auf einen vermeintlich untreuen Partner, oder die Freude über einen eingebildeten Erfolg kann sich bei erneutem Blick auf die Tatsachen als grundlos erweisen. Zum anderen sind Gefühle selbst Ausdruck von Wertungen, die wir selbst und andere Personen - auf der Grundlage von Standards, über die sich mit Gründen streiten lässt - wiederum als mehr oder weniger angemessen bewerten, die wir uns zu eigen machen, oder von denen wir uns distanzieren können. Gefühle weisen ein hohes Maß an Plastizität auf; wir können sie in

Dimensionen eines guten Lebens

Wohlbefinden 
vielfältiger Weise ausleben, kultivieren, vernachlässigen oder abwehren, um sie, bewusst oder unbewusst, mit unserem Identitätskonzept in Einklang zu bringen. Sie sind aber nicht beliebig formbar, und es bleibt nicht ohne Folgekosten, ihnen wiederholt die Möglichkeit des authentischen Ausdrucks zu versagen.

Lebenszufriedenheit: In der Lebensqualitätsforschung wird zu Recht unterschieden zwischen den tatsächlich erlebten Gefühlen von Glück und Unglück einerseits und der berichteten Lebenszufriedenheit andererseits. Schon das Erleben subjektiver Gefühle als solches ist von Vergleichen zwischen verschiedenen Situationen sowie zwischen Situationen und situationsbezogenen Erwartungen beeinflusst. Für die Lebenszufriedenheit, die subjektive Bewertung der eigenen Lebensqualität, sind Vergleichserfahrungen und Erwartungshaltungen erst recht maßgeblich. Diese Relativität der wahrgenommenen Lebensqualität erklärt, warum die Freude der Lottogewinnerin rasch abnimmt und nach kurzer Zeit dasselbe Niveau erreicht hat wie die Freude derjenigen, die nach einem Beinbruch die fortschreitende Selbstheilung ihres Körpers erlebt. Gemeinsam mit dem Umstand, dass wir uns eine Veränderung äußerer Bedingungen anscheinend besser vorstellen können als die Änderung unserer eigenen Erwartungen und Haltungen, erklärt diese Relativität auch eine generelle Neigung zu Fehlprognosen der eigenen Lebensqualität. So schätzen Personen, die sich vorstellen, mit einer Behinderung zu leben, die dann von ihnen wahrgenommene Lebensqualität systematisch schlechter ein, als sie von ihnen erlebt wird, wenn sie sich tatsächlich in der Situation wiederfinden (»disability paradox«; vgl. Albrecht/Devlieger 1999). Auf die Veränderung in unseren äußeren Lebensumständen fokussiert, fällt es uns schwer, die situationsbedingte Anpassung unserer eigenen Erwartungen in Rechnung zu stellen. Die subjektiv wahrgenommene Lebensqualität hängt offenbar stark von den Wertvorstellungen, dem normativen Selbstverständnis und der Lebenshaltung der Betroffenen ab. Daraus resultieren große interindividuelle Unterschiede in der Lebenszufriedenheit angesichts äußerlich vergleichbarer Lebensumstände, wie

Abb. 2.2: wir wiederum der Forschung zur Lebensqualität behinderter Personen Berichtete Lebensqualität bei Schlaganfallpatienten (aus Creutzfeldt entnehmen können.

So zeigt etwa die Befragung von Schlaganfallpatienten zwar eine deutliche Korrelation zwischen der wahrgenommenen Lebensqualität und dem anhand objektiver Indikatoren ermittelten Grad der Behinderung. 2017, S. 216). Mindestens ebenso auffallend ist jedoch die sehr große individuelle Vari-

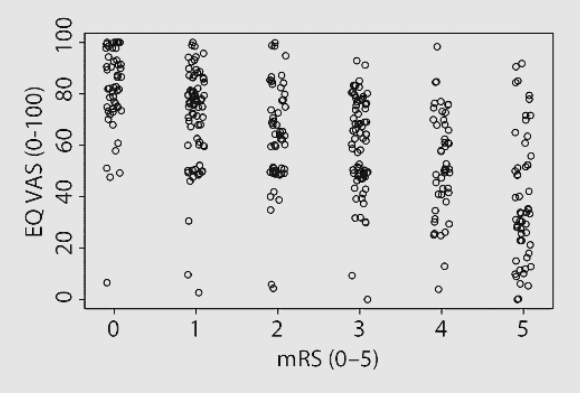
anz der Lebensqualitätsurteile bei identischem Behinderungsgrad, die sich bei stärkerer Behinderung sogar zunehmend bemerkbar macht. Abbildung 2.2 illustriert diesen Befund. Die horizontale Achse gibt (von 0 bis 5 zunehmend) den Grad der Behinderung gemäß der Rankin-Skala wieder; die vertikale Achse die berichtete Lebensqualität gemäß der europäischen Lebensqualitäts-Skala (European QoL visual analog scale, EQVAS). 
Zufriedenheit und Sinn: Auch Lebenszufriedenheit (als subjektiv wahrgenommene Lebensqualität) erschöpft offenbar nicht alles, was Personen für sich als Lebensziele oder als Kriterien eines schlechthin gelungenen Lebens in Erwägung ziehen. Viele Menschen nehmen - so scheint es wenigstens - freiwillig Einschränkungen ihrer eigenen Lebensqualität in Kauf. Sie scheinen dies aus verschiedenen Gründen zu tun; beispielsweise, um Ansprüchen persönlicher Integrität, Authentizität oder Selbstachtung gerecht $\mathrm{zu}$ werden, im Interesse anderer Personen oder im Interesse gemeinschaftlicher oder die eigene Lebenszeit überschreitender Projekte. Subjektives Glücksempfinden stellt anscheinend nicht die einzige Zutat eines (nach den eigenen Standards) gelungenen Lebens dar. Das Konzept eines guten Lebens scheint vielmehr unterschiedliche Sinndimensionen $\mathrm{zu}$ umfassen; unterschiedliche Hinsichten, in denen das eigene Leben rationalerweise als mehr oder weniger gelungen oder sinnvoll beurteilt werden kann. Für Entscheidungen zur Wahl oder Korrektur eines individuellen Lebensplans sind daher nicht nur Fragen der eigenen Lebensqualität, sondern vielfältige Deutungen des eigenen Lebenssinns relevant.

Grenzen des Hedonismus: Zur Verteidigung des Hedonismus ließe sich allerdings argumentieren, dass Personen in Wahrheit bzw. in letzter Hinsicht auch dort stets die Maximierung ihrer eigenen Lebensqualität anstrebten, wo sie ihr Glücksstreben vermeintlich zugunsten bestimmter Selbstbindungen (an eigene Selbstbilder, Lebensprojekte oder das Wohl anderer) zurückstellen. Sie handelten in Wahrheit aufgrund der Erwartung, dass die Verletzung dieser Bindungen noch größere Einbußen an Lebensqualität nach sich zöge als der unmittelbare Glücksverzicht; etwa aufgrund erwarteter Gewissensbisse. Ist dieser Einwand überzeugend? Stellen wir uns vor, Peter verzichtete auf die Realisierung eines innigen Lebenswunsches (etwa auf eine Karriere als Konzertpianist), um sich um seinen psychisch kranken Vater kümmern zu können. Paul böte Peter eine Droge an, durch die Peter seine emotionale Bindung an seinen Vater dauerhaft verlieren, ihn ohne Reue in einem Wohnheim unterbringen und seine Pianistenpläne realisieren könnte. Nehmen wir um des Arguments willen an, Peter selbst sei überzeugt, auf diese Weise sein eigenes Wohlgefühl steigern zu können. Trotzdem scheint es denkbar, dass er Pauls Angebot zurückweist. Mehr noch, es scheint denkbar, dass er dies unter Berufung auf seine eigene Vorstellung eines gelungenen Lebens tut; dass er es nicht nur als unvereinbar mit einer von außen an ihn gestellten Verpflichtung, sondern gewissermaßen als Verrat an sich selbst begreifen würde, auf den Vorschlag einzugehen. Falls die hedonistische Gleichsetzung eines gelungenen Lebens mit einem maximal angenehmen Leben berechtigt wäre, wäre dies jedoch unverständlich. Eine alternative Verteidigung des Hedonismus würde zwar akzeptieren, dass Menschen sich tatsächlich mitunter gegen die Maximierung ihrer eigenen Lebensqualität entscheiden, wie Peter dies im Gedankenexperiment tut. Sie würde dieses Verhalten aber als irrational bewerten. Für diese Behauptung wären allerdings gute Gründe anzuführen. Zugleich wären Einwände auszuräumen, denen sich der Hedonismus als solcher ausgesetzt sieht. So argumentiert Rössler unter Berufung auf die Bedeutung der Selbstbestimmung für die 
S. 96; Binnenzitat

Pippin 2004,

S. 188

Gutes Leben als autonom verantwortetes Projekt
Rössler 2017, "Autonomie ist wertvoll nicht nur, weil wir für unser Leben und für einzelne Hand-

Auffassung, man könne »ein sinnvolles Leben leben, ohne glücklich zu sein; aber nicht, ohne selbstbestimmt zu sein«:

lungen nur verantwortlich sein können, wenn wir sie selbst bestimmt haben und es tatsächlich in einem emphatischen Sinn unsere eigenen Handlungen sind, die wir ausführen. Würden wir beispielsweise manipuliert oder getäuscht, dann könnten wir uns selbst nicht als verantwortlich verstehen für unser Leben. Das bedeutet jedoch, dass ein solches nicht-eigenes Leben auch kein sinnvolles Leben wäre: Stellte ich nämlich fest, dass, wie Robert Pippin schreibt, idie ganze Schau letztlich oder grundlegend von anderen gesteuert oder durch institutionelle Einschränkungen fast völlig vorherbestimmt war, dann könnte mein Leben nicht den Sinn gehabt haben, von dem ich selbst ausgegangen war, könnte man ihm nicht die Bedeutung zuschreiben, die ich darin gefunden habe, und ist dadurch, durch solch eine Entdeckung, für mich seines Sinns beraubtı."

Selbstbestimmung: Die Bedeutung der Selbstbestimmung für die Möglichkeit eines sinnvollen Lebensplans ist relevant für die Frage, welche Rolle eine Ethik des guten Lebens in der Gegenwart überhaupt spielen kann. Seit Beginn der Neuzeit beginnt sich die Vorstellung durchzusetzen, dass nicht nur die objektiven Möglichkeiten der Realisierung von Konzepten des guten Lebens von der konkreten Lebenssituation abhängig und daher individuell höchst unterschiedlich sind, sondern dass auch diese Konzepte selbst und damit die Kriterien für ein gelungenes Leben innerhalb eines gewissen Rahmens der Selbstbestimmung des Individuums anheimgestellt sind. Allgemeingültige, für alle Menschen gleichermaßen zutreffende Aussagen können demnach bestenfalls den Charakter von Daumenregeln haben, die Ausnahmen nicht ausschließen. Ihrem Inhalt nach sind sie ohnehin auf wenige, basale Voraussetzungen eines guten Lebens beschränkt. Als Leitlinien der individuellen Lebensorientierung sind sie keineswegs ausreichend. Spezifischere Leitbilder eines guten Lebens werden demgegenüber unter dem Eindruck kultureller und sozialer Prägungen durch individuelle Selbstbindungen konstituiert. Durch ihre Entscheidungen und Kundgebungen, durch Bindungen an andere Menschen, an Projekte und Ideen bestimmen Personen zugleich ihre "praktische Identität" ("practical identity«; Korsgaard 1996, S. 101 u.v.a.). Im Verlauf ihrer Lebensgeschichte legen sie fest, bekräftigen (oder revidieren) als wer sie sich selbst verstehen und woran sie ihr eigenes Leben messen wollen. Die oben zitierte Argumentation Rösslers und Pippins soll die Auffassung stützen, dass es zu den Bedingungen eines sinnvollen Lebensplans gehört, vom betreffenden Individuum bewusst und selbstverantwortlich gestaltet zu werden. Dieser Bedingung kann auch die Wahl konventioneller Lebensziele genügen, jedoch nur in dem Maße, in dem sie angesichts eines offenen Horizonts alternativer Möglichkeiten selbstverantwortlich getroffen und in der selbstkritisch-reflektierenden Fortschreibung der eigenen Lebensgeschichte wiederholt bekräftigt wird. Aristoteles' Überzeugung, dass ein gelingendes menschliches Leben ein vernünftig reflektierendes Leben sein müsse, wird damit zwar als generelle Festlegung möglicher Inhalte eines guten Lebens be- 
stritten, bezüglich der Form eines menschlichen Lebens als eines reflektierten und selbstverantwortlich gewählten Lebens aber anerkannt. Um ein gutes Leben zu führen, müssen wir es nicht unbedingt gänzlich der Philosophie widmen; wohl aber scheint es erstrebenswert, unser Leben reflektiert, bewusst und selbstbestimmt zu führen.

Potentiale einer Ethik des guten Lebens: Sicher lassen sich der Tradition der Tugendethik und der zeitgenössischen Ethik des guten Lebens hilfreiche inhaltliche Daumenregeln bezüglich grundlegender Rahmenbedingungen eines glücklichen oder eines als sinnvoll erfahrenen Lebens entnehmen, etwa zum Wert der Freundschaft (NE, Buch VIII, 1155aff.) oder zur Bedeutung spezifischer Tugenden wie der Besonnenheit oder, jüngst wieder besonders im Fokus, der Gelassenheit (dazu schon Höffe 1993, S. 147 ff.). Solche Lebensweisheiten können nur den Charakter von Ratschlägen haben. Sie sind auf ihre Zeitgebundenheit zu überprüfen und, soweit sie auf empirische Annahmen gestützt sind, durch psychologische und sozialwissenschaftliche Forschung zu bestätigen (so mag die psychologisch orientierte empirische Glücksforschung manche von Aristoteles' Ausführungen zur Bedeutung von Freundschaften oder seine Skepsis gegenüber erwerbsorientierten, >materialistischen` Einstellungen bestätigen). Eigene Lebenserfahrung können sie freilich ebenso wenig ersetzen wie die etwa von den Künsten oder der Psychotherapie gebotenen Formen der Selbstbegegnung. Für die konkrete Lebensorientierung reichen sie allein nicht hin. Zumal angesichts der modernen Ausdifferenzierung von Kultursphären, innerhalb derer alternative Projekte eines guten Lebens angesiedelt sein können, kann keine Ethik des guten Lebens die Vielfalt an Möglichkeiten, dem individuellen Leben einen Sinn zu geben, vergleichend erfassen. Der eigene Lebensentwurf behält daher stets den Charakter eines innovativen, mehr oder weniger vorbildlosen Lebensexperiments (von "new and original experiments in living" spricht in ähnlichem Zusammenhang John St. Mill in On Liberty; Mill 1963 ff., S. 281). Damit wird keineswegs der Anspruch hinfällig, die eigenen Vorstellungen eines gelingenden Lebens überhaupt zu klären und sie vor dem Hintergrund möglicher Alternativen auf authentische, persönlich maßgebliche, rational nachvollziehbare und vertretbare Gründe zu beziehen.

Verwechslung von Zielen und Mitteln: Wo Aristoteles' spezifische Ratschläge auch aus heutiger Sicht unmittelbar plausibel scheinen, verdanken sie ihre Überzeugungskraft häufig der Kritik an der Verwechslung von Mitteln und Zwecken, die in technisierten, bürokratisierten und kapitalistischen Gesellschaften keine geringere Gefahr darstellt als seinerzeit (vgl. klassisch Simmel 2015, Bd.6). Aristoteles' Betonung des Werts von Tätigkeiten, die ihr Ziel in sich tragen, mag hier ebenso als Gegengift dienen wie Senecas Mahnung, der Grenzen des eigenen Lebens eingedenk zu sein (Seneca 1999, Bd.2, S. 175-239 [De brevitate vitae]). Zugleich spricht Aristoteles' Einsicht, dass die Möglichkeit eines guten Lebens von äußeren Lebensumständen abhängig ist, auch dafür, nicht nur in der eigenen Lebensorientierung das richtige Verhältnis zwischen Zwecken und Mitteln anzustreben, sondern auch durch Kulturkritik und gesellschaftliches Engagement der Verkehrung dieses Verhältnisses und den 
damit verbundenen Entfremdungsphänomenen entgegenzuwirken (siehe Kap. 11.3).

\subsection{3 | Tugendethik als Sittenlehre}

Alternative

Modelle des Verhältnisses zwischen Tugendethik und moderner Moralphilosophie

Kant und seine Anhänger/innen
Tugendethik als alternative Moraltheorie: Moderne Ansätze der Moralphilosophie begreifen moralische Rechte und Pflichten oft als normativen Rahmen, der Freiräume für die persönliche Lebensführung eröffnet. Dieses Verständnis legt es nahe, eine Tugendethik, die als Ethik des gelingenden Lebens interpretiert wird, als bloße Ergänzung der modernen Moralphilosophie zu verstehen. Da Letztere sich mit der Begründung des normativen Rahmens beschäftigt, während die Tugendethik Ratschläge gibt, wie dieser Rahmen klugerweise auszufüllen ist, kommen sie sich dieser Lesart zufolge gar nicht ins Gehege. Schärfere Kontroversen resultieren, wenn die Tugendethik nicht nur als Glückslehre, sondern auch als Sittenlehre verstanden wird. Sie steht dann in Konkurrenz zu den gegenwärtig vertretenen Modellen der Moralphilosophie.

Motivationstheoretische Ergänzung: Ein Konflikt zwischen moderner Moralphilosophie und Tugendethik ist vermeidbar, wenn tugendethische Überlegungen auf den Bereich der Motivationstheorie und Moralpädagogik beschränkt bleiben. Dann bleibt wechselseitige Ergänzung denkbar: Ein prinzipien- oder normenethischer Ansatz legt fest, was zu tun moralisch richtig ist; die Tugendethik untersucht, welche Haltungen der subjektiven Motivation zuträglich sind, das moralisch Richtige zu tun, in welchem Zusammenhang solche Haltungen mit der allgemeinen Lebensplanung stehen, und wie solche Haltungen gefördert werden können. Kant wirft in diesem Zusammenhang ein, dass es nur einen einzigen moralisch korrekten Grund geben kann, das moralisch Richtige zu tun, nämlich eben, dass es moralisch richtig ist. Die kantische Tugendlehre hat daher kein anderes Prinzip als die von Kant Rechtslehre genannte Disziplin, die sich mit den moralisch zulässigen und gebotenen Handlungstypen beschäftigt, nur dass dieses Prinzip in der kantischen Rechtslehre als Prinzip der äußeren Freiheit verstanden wird, in der kantischen Tugendlehre hingegen zugleich als Prinzip der subjektiven Handlungsmotivation. Tugendhaft ist ein Handeln aus Pflicht. Dass eine Handlung tatsächlich durch Pflicht motiviert und nicht nur zufälligerweise pflichtgemäß ist, ist dann am wahrscheinlichsten, wenn sie gegen den Widerstand egoistischer Neigungen vollzogen wird. In Kants Verständnis tut es deshalb der Tugendhaftigkeit einer Handlung keinen Abbruch, wenn sie mit Widerstreben vollzogen wird. Dass in der kantischen Dichotomie zwischen Pflicht und Neigung kein Raum für die differenzierende Würdigung verschiedener Arten von Neigungen vorgesehen ist, so dass Handeln aus krudem Egoismus und aus natürlichem Wohlwollen gleichermaßen in die moralisch anrüchige Kategorie eines Handelns saus Selbstlieber fallen, `wurmt « schon zeitgenössische Anhänger Kants (siehe Kap.6). Ein harmonischer Einklang von Neigung und Pflicht, dessen Idealbild unter dem Namen der sschönen Seele beschworen wurde, sei dem rigiden Pflichtethos eines seine innere Natur strikter Kontrolle unterwerfenden 
Vernunftmenschen vorzuziehen. Entsprechend haben auch einige Anhänger/innen Kants eine Ergänzung der kantischen Motivationstheorie durch tugendethische Überlegungen vorgeschlagen. In systematischer Hinsicht spricht tatsächlich nichts dagegen, Haltungen und Verhaltensweisen wie beispielsweise Hilfsbereitschaft, Wahrhaftigkeit, oder überhaupt die Bereitschaft zur moralischen Reflexion des eigenen Tuns so einzuüben, dass sie - ganz im Sinne des aristotelischen Tugendkonzepts - zur Quelle von Freude und gewissermaßen zur ‘zweiten Natur ‘ werden. Entscheidend ist nur, dass auch diese zweite Natur der vernünftigen Kritik und Korrektur zugänglich bleibt. Dies braucht nicht auf eine problematische >Vermischung der Triebfedern ‘ hinaus zu laufen - sofern denn die Kantische Vorstellung einer rein vernunftgezeugten Handlungsmotivation überhaupt haltbar ist.

Motivationstheoretische Alternative: Ob sie dies ist, ist allerdings umstritten. Elizabeth Anscombe (1958) vertritt in ihrem einflussreichen Beitrag Modern moral philosophy die These, dass die moderne Moralphilosophie fehl gehe, wenn sie kategorische, d. h. notfalls auch gegen alle eigenen Interessen zu befolgende, Normen postuliere. Die Idee der kategorischen Verbindlichkeit solcher Normen sei ein Relikt einer religiösen Gebotsethik. Sie verlören ihre motivationale Grundlage, wenn an einen mit uneingeschränkter Autorität und Zwangsgewalt ausgestatteten göttlichen Gesetzgeber nicht mehr geglaubt werde. Eine Tugendethik, die die Quelle sittlicher Tugend letztlich im eigenen Glücksstreben sieht, stehe hingegen auf einer stabilen motivationstheoretischen Grundlage. Anscombe scheint allerdings nicht einfach eine Rückkehr zum Modell der antiken Tugendethik anzustreben. Für dieses Zögern gibt es gute Gründe. So lässt sich fragen, inwieweit der Versuch, die Verbindlichkeit sittlicher Normen aus dem Glücksstreben der Handlungssubjekte herzuleiten, dem intersubjektiven Charakter moralischer Ansprüche gerecht werden kann. Ist eine Person, die andere grundlos schädigt oder quält, lediglich unklug oder närrisch? Wenn wir ihr den moralischen Vorwurf der Grausamkeit machen, scheinen wir nicht nur sagen zu wollen, dass sie ihr eigenes Glück verfehlt. Diesem Einwand lässt sich vielleicht entgegenhalten, dass die Unterscheidung zwischen dem individuellen Glück und dem Glück der Gemeinschaft gerade problematisch sei. Kants Gleichsetzung des von der Tugendethik thematisierten Glücksstrebens mit Egoismus sei daher unberechtigt. Tatsächlich geht die antike Tugendethik eher von einer Harmonie von Individualinteressen und Gemeinschaftsinteressen im Sinne eines organismischen Politikmodells aus. Darauf ließe sich einerseits erwidern, dass dieses Politikmodell konkurrierende Partikularinteressen faktisch nicht zum Verschwinden gebracht, sondern nur ideologisch verschleiert habe; Aristoteles' Lehre vom Sklaven von Geburt sei hierfür ein eindrückliches Beispiel. Andererseits ließe sich einräumen, dass es tatsächlich einer plausibleren motivationalen Grundlage für das Einnehmen eines unparteilichen Standpunkts bedarf, als ihn Kants Annahme einer rein vernunftgezeugten >Achtung vor dem Gesetz kann. Nach einer solchen Grundlage sucht beispielsweise die von Fichte und Hegel ausgehende Anerkennungstheorie (siehe Kap.7.1). In ihrem Rahmen lässt sich durchaus an tugendethische Überlegungen anknüpfen.

Elizabeth

Anscombe

Probleme der klassischen Tugendethik als Sittenlehre 
Michael Slotes radikales Gegenmodell zur modernen Moralphilosophie

Slote 2001, S. 5 / Slote 1997, S. 239
Akteursbasierter Ansatz: In direkte Konkurrenz zu späteren Modellen der Moralphilosophie tritt die Tugendethik, wenn sie selbst die Kriterien moralisch objektiv richtigen Handelns bestimmen soll. In modernen Konzeptionen der Moralphilosophie wie der Ethik Kants oder dem Utilitarismus ist Tugend der moralischen Richtigkeit systematisch nachgeordnet. Moralische Tugend bedeutet, habituell das Richtige zu tun, weil es richtig ist. Wir müssen daher wissen, was richtig ist, ehe wir wissen können, was tugendhaft ist. Eine radikale Gegenposition sieht die direkte Umkehrung des Verhältnisses zwischen Kriterien richtigen Handelns und Kriterien tugendhafter Gesinnung vor. Ihr zufolge ist das moralisch richtige Handeln dadurch gekennzeichnet, dass es aus einer tugendhaften Haltung hervorgeht. Wir benötigen dann zuerst Kriterien für die Tugendhaftigkeit von Haltungen, um daraus Kriterien für die Richtigkeit von Handlungen abzuleiten. Ein Vertreter dieser Auffassung ist Michael Slote, der diesbezüglich von einem akteursbasierten Ansatz (agent-based approach) spricht:

"An agent-based approach to virtue ethics treats the moral or ethical status of acts as entirely derivative from independent and fundamental aretaic (as opposed to deontic) ethical characterizations of motives, character traits, or individuals."

Befürworter/innen dieser Position nehmen erstens an, dass eine Orientierung gemäß dem akteursbasierten Ansatz besser als andere Ansätze in der Lage sei, mit der nötigen Flexibilität auf unterschiedliche Handlungssituationen zu reagieren. Denn die primären Gegenstände der ethischen Bewertung seien allgemeine charakterliche Haltungen, die vermöge individueller Urteilskraft mit konkreten Situationen vermittelt würden. Zweitens betonen sie, dass die moralische Beurteilung von Handlungen nicht von der Beurteilung der Haltung abgelöst werden könne, aus der die Handlungen resultieren. Ob mit den beiden genannten Punkten tatsächlich Differenzen bezeichnet werden, ist allerdings fraglich. Hinsichtlich der zweiten Überlegung besteht jedenfalls kein Dissens zwischen dem akteursbasierten Ansatz und etwa der Position Kants. Kant unterscheidet ja gerade zwischen einem nur objektiv richtigen (pflichtgemäßen) und einem moralisch guten Handeln (aus Pflicht) und definiert Letzteres durch die Qualität des subjektiven Handlungsprinzips, das Kant »Maxime" nennt (zur Nähe zwischen Maximen und grundlegenden charakterlichen Haltungen bzw. Tugenden vgl. Höffe 1979, S. 89 ff.). Die moralische Bedeutung von Gesinnung und Charakter ist also zwischen den Parteien gar nicht strittig. Was die Flexibilität betrifft, mit der das ethische Urteilsvermögen auf unterschiedliche Handlungssituationen reagieren kann, bleibt zumindest unklar, warum ein akteursbasierter Ansatz grundsätzliche Vorteile gegenüber einer Ethik aufweisen sollte, die die Erkenntnis des Richtigen als vorrangig gegenüber der Erkenntnis des Tugendhaften ansieht. Denn auch Letztere kann die als richtig erkannten Prinzipien oder Normen als mehr oder weniger generelle und abwägungsbedürftige >Prima-facie`-Orientierungen konzipieren. Auch sie kann also der individuellen Urteilskraft eine mehr oder weniger große Rolle bei der konkreten Handlungsorientierung zuweisen. In jedem Fall wäre zunächst 
zu klären, welches Maß an `Flexibilität` normative Ethik überhaupt ermöglichen soll.

Priorität von Tugend oder Handlungsrichtigkeit: Der entscheidende Unterschied zwischen dem akteursbasierten Ansatz und der etwa von Kant vertretenen Position besteht darin, dass Kant zwischen der objektiven Richtigkeit der Handlung (die sich unabhängig von der Gesinnung feststellen lässt) und ihrer Tugendhaftigkeit (die von der Gesinnung abhängig ist, das objektiv Richtige zu tun) unterscheidet (Ricken 2013, S. 257 f.). Demgegenüber betrachtet der akteursbasierte Ansatz die moralische Qualität einer Handlung als vollständig (entirely, s.o.) abhängig von der sittlichen Qualität der Gesinnung oder Haltung, aus der die Handlung resultiert. Dabei soll die Qualität der Gesinnung unabhängig von Kriterien der Handlungsbeurteilung festzustellen sein.

Handlungsunabhängige Tugendkriterien? Diese Auffassung erscheint problematisch. Es ist schwer zu sehen, wie sich sowohl plausible als auch hinreichend präzise Kriterien für tugendhafte Haltungen definieren lassen, die nicht implizit schon Kriterien für richtige Handlungen voraussetzen. Die Mesotes-Lehre erscheint für den Zweck zu unspezifisch, auch ist sie nur innerhalb bestimmter Grenzen plausibel (Schneewind 1990). Überzeugend wirkt sie am ehesten im Kontext diätetisch-medizinischer oder psychologischer Harmoniekonzepte und damit eher für den Bereich der Glückstugenden: Für das eigene Wohlbefinden mag es tatsächlich hilfreich sein, weder zu viel noch zu wenig zu essen, zu schlafen, oder den Körper zu belasten, und vermutlich gilt Ähnliches auch in Bezug auf Mut und Feigheit. Für den Bereich sozialmoralischer Tugenden versucht Tugendhat, die Lehre von der goldenen Mitte auf ein an Erich Fromms Moralpsychologie orientiertes Modell einer angemessenen sozialen Distanz zu beziehen. Die goldene Mitte soll in diesem Sinne eine Haltung gegenüber anderen Menschen bezeichnen, die von distanzloser Symbiose gleich weit entfernt ist wie von kalter Indifferenz (Tugendhat 1993, S. 250-281). Präzisere Konturen gewinnt diese Lösung jedoch erst dadurch, dass Tugendhat sie in Richtung einer Anerkennungstheorie weiterentwickelt und dabei auch an moralphilosophische Konzepte der Unparteilichkeit anknüpft, wie sie etwa von Adam Smith und Kant entwickelt worden sind. Tugendhats Lösung zielt damit erklärtermaßen nur auf die Plausibilisierung eines Ergänzungsverhältnisses zwischen Tugendethik und moderner Moralphilosophie, nicht auf die Etablierung einer tugendethischen Alternative zur Letzteren (ebd., S. 282-309). Die Berufung auf moralische Vorbilder oder maßgebliche ethische Traditionen kann das Kriterienproblem ebenfalls nicht lösen, sondern verschiebt es nur auf die Frage nach Kriterien für die Vorbildhaftigkeit persönlichen Verhaltens oder die Maßgeblichkeit ethischer Traditionen.

Unterbestimmtheit des akteursbasierten Ansatzes: Fragen lässt sich zudem, ob die von ihren Vertreter/innen betonte Flexibilität der Tugendethik nicht zu weit geht. Denn charakterliche Haltungen - etwa eine Haltung des Mutes, der Aufrichtigkeit oder der Loyalität - können sehr unterschiedliche Handlungen motivieren. Wie lässt sich vor diesem Hintergrund sicherstellen, dass aus einer tugendhaften Haltung ausschließlich richtige Handlungen resultieren? Der akteursbasierte Ansatz wäre 
Vagheit der akteursbasierten Ethik nur plausibel, wenn er beispielsweise die Aussageverweigerung des Auftragsmörders nicht als Ausdruck von Loyalität (Tugend) deklariert, sondern von blinder Komplizenschaft (Untugend). Es ist jedoch schwer zu sehen, wie sich Loyalität von Komplizenschaft klar genug abgrenzen lässt, ohne auf Kriterien für die Beurteilung von (paradigmatischen) Handlungen zu rekurrieren. Ein denkbarer Lösungsversuch basiert auf der Annahme einer Einheit der Tugenden: Wer eine Tugend besitzt, besitzt alle Tugenden, und wer nicht alle Tugenden besitzt, besitzt gar keine Tugend. Demnach könnte beispielsweise nicht loyal genannt werden, wer nicht zugleich über ein waches Gerechtigkeitsempfinden verfügt. Die Lösung setzt allerdings zweierlei voraus. Erstens wäre von einer Tugendliste zu zeigen, dass sie vollständig ist. Zweitens wäre zu zeigen, dass eine Person, die über alle Einzeltugenden verfügt, im Stande ist, die verschiedenen Teil-Tugenden (z. B. Nachsicht und mutiges Eintreten für Gerechtigkeit) stets korrekt abzuwägen. Dabei müsste sich die Korrektheit der Abwägung allein anhand von Kriterien prüfen lassen, die auf Charakter oder Haltungen der handelnden Person bezogen sind. Dies scheint zumindest keine leichte Aufgabe. Ein Indiz dafür ist, dass Slote selbst gelegentlich handlungsbezogene Kriterien in seine Tugendbeschreibungen einschmuggelt; etwa dort, wo er die Tugend eines Strafverfolgers als »concern for doing his job and playing the contributing social role that involves« (Slote 1997, S. 242) definiert und somit von Kriterien der Berufs- oder Rollenkonformität des Verhaltens abhängig macht.

Richtig versus gutgemeint: Eine weitere Herausforderung für den akteursbezogenen Ansatz liegt darin, einer verbreiteten Intuition gerecht zu werden, der zufolge wir zwischen einem objektiv richtigen und einem nur gutgemeinten Handeln unterscheiden müssen. Selbst eine Akteurin mit vollkommenem Charakter wäre nicht allwissend. Aufgrund ihrer Wissensschranken mag sie snach bestem Wissen und Gewissen Entscheidungen treffen, die sie bei vollständiger Kenntnis aller Umstände nicht getroffen hätte und die sie nachträglich bedauern mag. Ansätze moderner Moralphilosophie, die zwischen der objektiven Richtigkeit der Handlung und der Tugendhaftigkeit der Gesinnung unterscheiden, bieten in solchen Fällen die Möglichkeit, die tatsächlich getroffenen Entscheidungen als zwar falsch aber entschuldbar zu charakterisieren. Der akteursbezogene Ansatz muss jedoch anscheinend alle Handlungen als moralisch fehlerlos betrachten, deren Motive untadelig waren. Wenn die Handlungsbeurteilung vollständig von der Gesinnung abhängt, kann nicht mehr zwischen guten und nur gutgemeinten Handlungen unterschieden werden.

Ausblick: Die griechische Philosophie tritt mit dem Anspruch an, die unkritische Orientierung an Mythos und Religion, an Traditionen und Konventionen durch rationale, argumentativ verteidigbare Orientierungen zu ersetzen. Logos und physis - die Vernunft der sprachlichen Verständigung und die intrinsische Rationalität der als wohlgeordneter Kosmos interpretierten Natur - bilden dabei die normativen Bezugspunkte. Die naturalistische Traditionslinie verdankt ihre nachhaltige Wirkung wesentlich Platons Ideenlehre und deren aristotelischer Weiterentwicklung zu einer Theorie der Entelechien, die den Dingen zugleich als ihre 'wahre Natur innewohnen, ihre zielgerichtete Entwicklung erklären und 
das für sie jeweils Gute definieren sollen. Aristoteles' Ethik ist jedoch nicht nur eine Anwendung seiner Naturphilosophie. Sie umfasst auch davon unabhängige systematische Reflexionen auf das Wesen des menschlichen Handelns, auf Urteilskraft und Verantwortlichkeit, auf das Wesen politischer Institutionen, die Aufgaben und Grenzen philosophischer Ethik, auf Tugend, Gerechtigkeit und zumal auf Begriff, Form und Elemente eines gelingenden Lebens. Die begrifflichen und sachlichen Erträge dieser Reflexionen prägen die Diskussion bis in die Gegenwart.

Generell ist für die antike Tugendethik kennzeichnend, dass Fragen des moralisch Richtigen und Gerechten nicht scharf von Fragen des guten Lebens abgegrenzt werden. Im Zentrum steht die Orientierung am Ziel des guten und glücklichen Lebens. Dabei wird die Wahrung des Rechten und Schicklichen entweder als ein integrales Element dieser Orientierung am Ziel des glücklichen Lebens verstanden (so bei Aristoteles). Oder das glückliche Leben wird vollständig mit dem sittlich richtigen, vernünftigen und natürlichen Leben gleichgesetzt (so in der Stoa). Diese Versuche einer Harmonisierung des Guten und des Gerechten erscheinen zwar schon manchen Zeitgenossen als gezwungen. Radikal zurückgewiesen werden sie neuzeitlichen Denkern wie Thomas Hobbes, in einer Zeit, in der die Konflikte zwischen Individuum und Gemeinschaft (noch) deutlicher zutage treten und organismische Politikmodelle an Überzeugungskraft verlieren. Die Frage nach der Form eines guten Lebens wird damit jedoch nicht obsolet; ebenso wenig die Frage, wie Glücksstreben und Moral zu vermitteln sind. Heutige Versuche, an die antiken Tugendethiken und die mit ihnen verknüpfte Politik- und Institutionentheorie anzuknüpfen, begreifen diese Ethiken mitunter nur als Ergänzung, mitunter aber auch als systematische Alternative zur modernen, primär gerechtigkeitsorientierten normativen Ethik und politischen Philosophie.

\section{Siglenverzeichnis}

AA - Akademieausgabe (Kant)

DK - Diels/Kranz, Die Fragmente der Vorsokratiker

$\mathrm{KpV}$ - Kritik der praktischen Vernunft (Kant, AA, V, S. 1-163)

KSA - Kritische Studienausgabe (Nietzsche 1988)

NE - Nikomachische Ethik (Aristoteles)

SEP - Stanford Encyclopedia of Philosophy (Zalta)

\section{Einführende Literatur}

Barnes, Jonathan: Aristotle: A Very Short Introduction. Oxford/New York 1996.

Crisp, Roger/Slote Michael (Hrsg.): Virtue Ethics. Oxford 1997.

Darwall, Stephen L. (Hrsg.): Virtue Ethics. Malden 2003.

Gigon, Olof: Einführung. In: Aristoteles: Die Nikomachische Ethik. München

72006, S. 5-102.

Haybron, Daniel M.: »Happiness«. In: SEP 2011.

Höffe, Otfried: Aristoteles. München ${ }^{4} 2014$.

Horn, Christoph: Antike Lebenskunst: Glück und Moral von Sokrates bis zu den Neuplatonikern. München 1998.

Rapp, Christof/Corcilius, Klaus: Aristoteles Handbuch: Leben - Werk - Wirkung. Stuttgart ${ }^{2} 2021$.

Ricken, Friedo: Allgemeine Ethik. Stuttgart u. a. ${ }^{5} 2013$.

Rippe, Klaus P./Schaber, Peter (Hrsg.): Tugendethik. Stuttgart 1998.

Wall, Steven: »Perfectionism in Moral and Political Philosophy«. In: SEP 2017. 
Welzel, Hans: Naturrecht und materiale Gerechtigkeit. Göttingen ${ }^{4} 1962$.

Wolf, Ursula: Aristoteles' >Nikomachische Ethikı. Darmstadt ${ }^{3} 2013$.

\section{Zitierte und weiterführende Literatur}

Albrecht, Gary L./Devlieger, Patrick J.: »The disability paradox: high quality of life against all odds«. In: Social Science \& Medicine 48/8 (1999), S. 977-988.

Annas, Julia: The Morality of Happiness. Oxford/New York 1993.

Anscombe, Elizabeth M.: »Modern Moral Philosophy«. In: Philosophy 33 (1958), S. 1-19.

Apel, Karl-Otto: Paradigmen der Ersten Philosophie. Frankfurt a. M. 2011.

Aristoteles: Werke in deutscher Übersetzung. Berlin $1956 \mathrm{ff}$.

Aristoteles: Nikomachische Ethik. Reinbek bei Hamburg ${ }^{5} 2006$.

Brecht, Bertolt: Werke. Große kommentierte Berliner und Frankfurter Ausgabe. Berlin/Weimar 1988

Chappell, Timothy (Hrsg.): Values and Virtues: Aristotelianism in Contemporary Ethics. Oxford 2006.

Creutzfeldt, Claire J.: »Schlaganfall«. In: Erbguth, Frank/Jox, Ralf J. (Hrsg.): Angewandte Ethik in der Neuromedizin. Berlin/Heidelberg 2017, S. 213-220 (doi:10.1007/978-3-662-49916-0_19).

Crisp, Roger: Reasons and the Good. Oxford/New York 2006.

Diels, Hermann/Kranz, Walther (Hrsg.): Die Fragmente Der Vorsokratiker, Griechisch und Deutsch. Berlin ${ }^{8} 1956$ [DK].

Forschner, Maximilian: Die stoische Ethik. Stuttgart ${ }^{2} 1995$.

Frankena, William K.: Ethics. Englewood Cliffs 1973.

Frankfurt, Harry G.: »Alternate Possibilities and Moral Responsibility«. In: The Journal of Philosophy 66 (1969), S. 829-839.

Gabriel Gottfried: „Solipsismus«. In: Ritter, Joachim/Gründer, Karlfried (Hrsg.): Historisches Wörterbuch der Philosophie. Basel/Stuttgart 1972 ff., Bd. 9, Sp. 1018-1023.

Gaus, Gerald F.: »What is Deontology?«In: The Journal of Value Inquiry 35 (2001), S. 27-42 und 179-193 (2 Teile).

Gigon, Olof: Einführung. In: Aristoteles: Die Nikomachische Ethik. München ${ }^{7} 2006$, S. 5-102.

Hardie, William F.: »The Final Good in Aristotle’s Ethics«. In: Philosophy 40/154 (1965), S. 277-295.

Haybron, Daniel M.: The Pursuit of Unhappiness: The Elusive Psychology of Well-Being. Oxford 2008.

Henning, Christoph: Freiheit, Gleichheit, Entfaltung: Die politische Philosophie des Perfektionismus. Frankfurt a. M. 2015.

Herman, Barbara: The Practice of Moral Judgment. Cambridge 1993.

Höffe, Otfried: Ethik und Politik: Grundmodelle und -probleme der praktischen Philosophie. Frankfurt a. M. 1979.

Höffe, Otfried: Moral als Preis der Moderne: Ein Versuch über Wissenschaft, Technik und Umwelt. Frankfurt a. M. 1993.

Holl, Jann: Historische und systematische Untersuchungen zum Bedingungsverhältnis von Freiheit und Verantwortlichkeit. Königstein 1980.

Honneth, Axel: Kampf um Anerkennung: Zur moralischen Grammatik sozialer Konflikte. Frankfurt a. M. 1992a.

Honneth, Axel (Hrsg.): Kommunitarismus: Eine Debatte über die moralischen Grundlagen moderner Gesellschaften. Frankfurt a. M./New York 1992b.

Hurka, Thomas: Perfectionism. Oxford 1993.

Illies, Christian: The Grounds of Ethical Judgement: New Transcendental Arguments in Moral Philosophy. Oxford 2003.

Jaeger, Werner: Paideia: Die Formung des griechischen Menschen. Berlin/New York 1973.

Kant, Immanuel: Gesammelte Werke: Akademieausgabe. Berlin 1902 ff. 
Korsgaard, Christine M.: The Sources of Normativity. Cambridge 1996.

MacIntyre, Alasdair C.: After Virtue: A Study in Moral Theory. Notre Dame ${ }^{3} 2007$.

McKenna, Michael/Coates, D. Justin: »Compatibilism«. In: SEP 2015.

Mill, John St.: Collected Works. Toronto $1963 \mathrm{ff}$.

Nagel, Thomas: The View from Nowhere. Oxford/New York 1986.

Nestle, Wilhelm: Die Vorsokratiker. Jena 1908.

Nietzsche, Friedrich: Sämtliche Werke: Kritische Studienausgabe in 15 Einzelbänden (KSA). Hrsg. von Giorgio Colli und Mazzino Montinari. München/Berlin/ New York ${ }^{2} 1988$.

Pippin, Robert B.: »Sinn und Moral«. In: Ders. Moral und Moderne: Die Welt von Henry James. München 2004, S. 187-196.

Platon: Sämtliche Werke in zehn Bänden. Übers von. Friedrich Schleiermacher. Reinbek bei Hamburg 2004.

Popper, Karl R.: Die offene Gesellschaft und ihre Feinde 1: Der Zauber Platons. In: Ders.: Gesammelte Werke, Bd. 5. Tübingen ${ }^{8} 2003$ (EA: The Open Society and its Enemies, Bd. I: The Spell of Plato. London 1945).

Rawls, John: Eine Theorie der Gerechtigkeit. Frankfurt a. M. 1975.

Rawls, John: Die Idee des politischen Liberalismus. Frankfurt a. M. 1992.

Rawls, John: Politischer Liberalismus. Frankfurt a. M. 1998.

Reese-Schäfer, Walter: Grenzgötter der Moral: Der neuere europäisch-amerikanische Diskurs zur politischen Ethik. Frankfurt a. M. 1997.

Ricken, Friedo: »Wert und Wesen der Lust«. In: Höffe, Otfried (Hrsg.): Die Nikomachische Ethik. Berlin 1995, S. 207-228.

Ricken, Friedo: Allgemeine Ethik. Stuttgart u. a. ${ }^{5} 2013$.

Ritter, Joachim: »Ethik I-VI«. In: Ders. (Hrsg.): Historisches Wörterbuch der Philosophie, Bd. 2. Basel/Stuttgart 1971, Sp. 759-795.

Rössler, Beate: Autonomie: ein Versuch über das gelungene Leben. Berlin 2017.

Rorty, Amélie O. (Hrsg.): Essays on Aristotle’s Ethics. Berkeley 1980.

Schnädelbach, Herbert: „Was ist Neoaristotelismus?« In: Kuhlmann, Wolfgang (Hrsg.): Moralität und Sittlichkeit. Frankfurt a. M. 1986, S. 38-63.

Schneewind, Jerome B.: »The Misfortunes of Virtue«. In: Ethics 101/1 (1990), S. 42-63 (Nachdruck in Crisp/Slote 1997, S. 178-200).

Seel, Martin: Versuch über die Form des Glücks. Frankfurt a. M. 1995.

Seneca, Lucius A.: Philosophische Schriften: lateinisch und deutsch. Darmstadt 1999.

Simmel, Georg: Gesamtausgabe in 24 Bänden. Berlin 2015.

Slote, Michael: »Agent-based Virtue Ethics«. In: Crisp/Slote (1997), S. 239-262.

Slote, Michael: Morals from Motives. Oxford 2001.

Snell, Bruno. Die Entdeckung des Geistes: Studien zur Entstehung des europäischen Denkens bei den Griechen. Hamburg ${ }^{2} 1948$.

Stock, St. George: Stoicism. London 1908.

Taylor, Charles: »Die Motive einer Verfahrensethik«. In: Kuhlmann, Wolfgang (Hrsg.): Moralität und Sittlichkeit. Frankfurt a. M. 1986, S. 101-135.

Thomas von Aquin: Die deutsche Thomas-Ausgabe. Graz/Wien/Köln 1933 ff.

Tugendhat, Ernst: Vorlesungen über Ethik. Frankfurt a. M. 1993.

Van Inwagen, Peter: An Essay on Free Will. Oxford 1983.

Windelband, Wilhelm: Lehrbuch der Geschichte der Philosophie. Tübingen ${ }^{6} 1912$.

White, Nicholas: »Socrates in Hegel and Others«. In: Ahbel-Rappe, Sara/Kamtekar, Rachana (Hrsg.): A Companion to Socrates. Malden MA 2006, S. 368-385.

Zalta, Edward N. (Hrsg.): The Stanford Encyclopedia of Philosophy. In: https:// plato.stanford.edu/. 
Open Access Dieses Kapitel wird unter der Creative Commons Namensnennung 4.0 International Lizenz (http://creativecommons.org/licenses/by/4.0/deed.de) veröffentlicht, welche die Nutzung, Vervielfältigung, Bearbeitung, Verbreitung und Wiedergabe in jeglichem Medium und Format erlaubt, sofern Sie den/die ursprünglichen Autor(en) und die Quelle ordnungsgemäß nennen, einen Link zur Creative Commons Lizenz beifügen und angeben, ob Änderungen vorgenommen wurden.

Die in diesem Kapitel enthaltenen Bilder und sonstiges Drittmaterial unterliegen ebenfalls der genannten Creative Commons Lizenz, sofern sich aus der Abbildungslegende nichts anderes ergibt. Sofern das betreffende Material nicht unter der genannten Creative Commons Lizenz steht und die betreffende Handlung nicht nach gesetzlichen Vorschriften erlaubt ist, ist für die oben aufgeführten Weiterverwendungen des Materials die Einwilligung des jeweiligen Rechteinhabers einzuholen. 